\title{
Distribution of intermediate water masses in the subtropical northeast Atlantic
}

\author{
I. Bashmachnikov ${ }^{1,2,3}$, Â. Nascimento ${ }^{1}$, F. Neves ${ }^{1}$, T. Menezes $^{1}$, and N. V. Koldunov ${ }^{4}$ \\ ${ }^{1}$ MARE - Marine and Environmental Sciences Centre, Faculdade de Ciências, Universidade de Lisboa, Campo Grande, \\ 1749-016 Lisbon, Portugal \\ ${ }^{2}$ Departamento de Engenharia Geográfica, Geofísica e Energia (DEGGE), Faculdade de Ciências, Universidade de Lisboa, \\ Campo Grande, 1749-016 Lisbon, Portugal \\ ${ }^{3}$ Laboratory of Oceanography at the Institute of Earth Science of the St. Petersburg State University (SPbSU), \\ 10th line 33/35, St. Petersburg, Russia \\ ${ }^{4}$ Climate Service Center Germany (GERICS), Helmholtz-Zentrum Geesthacht, Hamburg, Germany \\ Correspondence to: I. Bashmachnikov (igorb@fc.ul.pt)
}

Received: 2 April 2015 - Published in Ocean Sci. Discuss.: 21 May 2015

Revised: 17 September 2015 - Accepted: 18 September 2015 - Published: 9 October 2015

\begin{abstract}
This work presents the quantitative study of climatological distributions of mid-depth source water types in the northeast (NE) Atlantic using the optimum multiparameter analysis (OMP). It generalises a number of regional results from particular synoptic sections. The cores of the Mediterranean Water (MW), the modified Antarctic Intermediate Water (mAAIW) and the Subarctic Intermediate Water (SAIW) are detected and spatial variations of their depth/density are obtained: as expected, spreading of the water types is predominantly isopycnic and follows the major mid-depth circulation patterns. In some areas the turbulent transport also makes a considerable contribution. MW in the Atlantic spreads in three cores of different density: the upper MW core (northwest of the line $28^{\circ} \mathrm{W}, 35^{\circ} \mathrm{N}-$ $14^{\circ} \mathrm{W}, 44^{\circ} \mathrm{N}$ ) is found in the neutral density range of $27.65-$ $27.70 \mathrm{~kg} \mathrm{~m}^{-3}$ at depths of $900-1000 \mathrm{~m}$; the main MW core (between the line above and the line $35^{\circ} \mathrm{W}, 28^{\circ} \mathrm{N}-10^{\circ} \mathrm{W}$, $37^{\circ} \mathrm{N}$ ) has neutral density of around $27.75 \mathrm{~kg} \mathrm{~m}^{-3}$ and is found at $1000-1100 \mathrm{~m}$; the lower MW core (southeast of the line $35^{\circ} \mathrm{W}, 28^{\circ} \mathrm{N}-10^{\circ} \mathrm{W}, 37^{\circ} \mathrm{N}$ ) has neutral density of around $27.80 \mathrm{~kg} \mathrm{~m}^{-3}$ and is found at $1250-1350 \mathrm{~m}$. The upper MW core has a comparatively low MW content (below $30 \%$ ) and is speculated to be transported by the mean flow from the northern Iberian Peninsula and the Bay of Biscay to the northern Azores. The main MW core contains the majority of the outflowing MW. It primarily originates from the Mediterranean undercurrent around Estremadura Promon-
\end{abstract}

tory, where the Joint Effect of Baroclinicity and Bottom Relief (JEBAR) overrides the topographic $\beta$ effect. It is transported west to the Azores Islands mostly along $39^{\circ} \mathrm{N}$. The lower MW core originates in the Gulf of Cádiz, from where it is transported by the dominating flows southwestwards. The SAIW core is detected between 27.70 and $27.75 \mathrm{~kg} \mathrm{~m}^{-3}$. It is found to spread south along both slopes of the MidAtlantic Ridge (MAR). SAIW east of the MAR mixes with the upper and the main MW cores and re-circulates in a cyclonic gyre at $15-25^{\circ} \mathrm{W}$ and $34-39^{\circ} \mathrm{N}$, penetrating as far south as the Azores Current. The mAAIW core is detected between 27.60 and $27.65 \mathrm{~kg} \mathrm{~m}^{-3}$. Its northernmost spreading limit is between 25 and $29^{\circ} \mathrm{N}$, but its influence can be observed along the African coast and immediately west of the Canary Islands up to $32^{\circ} \mathrm{N}$. The maximum concentration of the mAAIW core is found south of the Canary Islands, from where mAAIW is advected westwards, along with the westward spreading of the deep fraction of MW.

\section{Introduction}

Thermohaline properties of deep oceanic waters are formed in the upper mixed layer under the effects of the solar radiation balance and the heat/fresh water exchanges between the ocean and the atmosphere. Some of the near-surface water is subducted to deeper ocean layers as a result of downwards 
Table 1. List of the main acronyms.

\begin{tabular}{ll}
\hline mAAIW & modified Antarctic Intermediate Water \\
AAIW & Antarctic Intermediate Water \\
H & $\begin{array}{l}\text { North Atlantic Central Water, the maximum } \\
\text { inflection point }\end{array}$ \\
LSW & Labrador Sea Water \\
MAR & Mid-Atlantic Ridge \\
MW & Mediterranean Water \\
NACW & North Atlantic Central Water \\
NADW & North Atlantic Deep Water \\
OMP & Optimum multiparameter \\
SAIW & Subarctic Intermediate Water \\
StrMW & subtropical mode water \\
\hline
\end{tabular}

Ekman pumping or deep winter convection. The first mechanism (the ventilated thermocline) is only active where wind stress curl is negative (Pedlosky, 1998). The most favourable subduction conditions form in regions with substantial horizontal tilt of near-surface isopycnals, allowing isopycnic downward motion. In the northeast (NE) Atlantic these conditions are met along the frontal zones of the branches of the North Atlantic Current (Tomczak and Godfrey, 2003; Cianca et al., 2009), where various modes of the North Atlantic Central Water (NACW) are formed. Subduction is the most efficient in winter, when the internal water structure is not sheltered by the seasonal pycnocline. The deep convection is a result of the gravitational instability and is mostly active in weakly stratified polar waters in winter due to an intensive heat loss and water salinification during ice formation (van Aken, 2000a).

Below the seasonal pycnocline, having lost connection with the ocean surface, water changes its thermohaline properties mainly as a result of its mixing with waters of different properties. When a subduction/convection process is regular, large collections of water parcels with a common formation history form. Those are known as the source water types (Tomczak and Large, 1989). They can spread long distances across the ocean without undergoing significant changes in their properties.. Formed as a result of local vertical mixing, the cores of the source water types form local minima in potential vorticity.

This work examines the distributions of water types in the subtropical NE Atlantic ( $25-45^{\circ} \mathrm{N}$ and $\left.5-35^{\circ} \mathrm{W}\right)$. Some general features of the distributions are described in a number of studies (Tsuchiya et al., 1992; Pérez et al., 1998, 2001; Poole and Tomczak, 1999; van Aken, 2000a, b, 2001; Cabeçadas et al., 2002; Alvaréz et al., 2004; Barbero et al., 2010; Louarn and Morin, 2011). However, the early works only present qualitative descriptions of the distributions of water types, and are mostly based on subjective criteria. The more recent works apply qualitative estimates (mostly based on the optimum multiparameter (OMP) analysis), but only to particular synoptic sections. Yet, a quantitative description of climato-

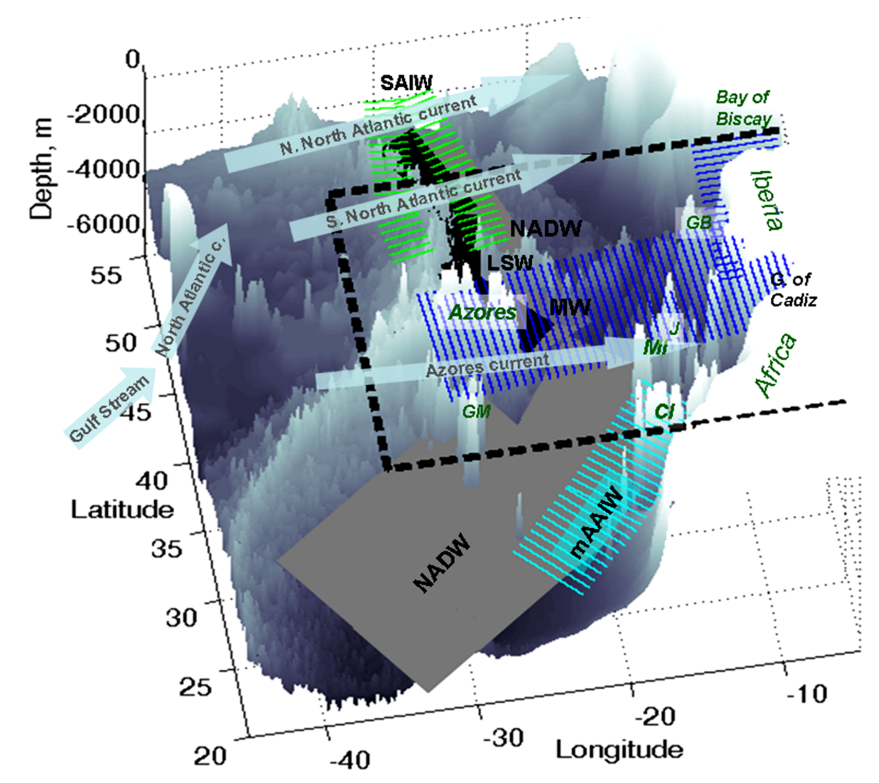

Figure 1. Bathymetry and distributions of the main water types below the main thermocline (MW - blue, SAIW - green, mAAIW cyan, LSW - black, NADW $\mathrm{u}$ - grey). The study region is demarcated by the black dashed lines. Intersections of the black dashed lines with the water types represent the areas where water types enter into the study region. The main thermocline water types, generated in the western Atlantic, enter the study region with the surface currents marked with semi-transparent arrows. CI are Canary Islands, MI - Madeira Island, GM - Great Meteor Seamount, J Josephine Seamount, GB - Galicia Bank.

logical distributions of mid-depths water types has not been performed. The present study, being a generalisation of the previous works, also defines the depths of the cores of each of the mid-depth water types, and refines the limits of their spreading. Additionally, a detailed description of the changes in the water type, presented as percentages with the distance from the source, is also reported. Detailed knowledge of the distributions of water types permits a view of the major pathways of water particles across the mid-depth ocean, which is otherwise too slow and turbulent to confidently derive such pathways from the limited number of observations currently available. The detailed distributions can be further used for studies of diapycnal and along-isopycnal mixing intensities in the study region.

Below we present a brief overview of water types in the subtropical NE Atlantic. The list of the main acronyms is presented in Table 1. Their known distributions are schematically summarised in Fig. 1.

\subsection{Upper water masses: NACW}

The principal water mass of the North Atlantic main thermocline, the NACW, is composed of various fractions, or modes, formed in different areas of the North Atlantic (Table 2). NACW is characterised by a nearly straight line in 
Table 2. Source water type characteristics for the subtropical mode water (StrMW), the North Atlantic Central Water $(\mathrm{NACW}, \mathrm{H}$ and $\mathrm{NACW}_{1}$ ), the Mediterranean Water (MW), the modified Antarctic Intermediate Water (mAAIW), the Subarctic Intermediate Water (SAIW), the Labrador Sea Water (LSW), and the upper North Atlantic Deep Water $\left(\mathrm{NADW}_{\mathrm{u}}\right)$.

\begin{tabular}{|c|c|c|c|c|c|c|}
\hline $\begin{array}{l}\text { Water } \\
\text { type }\end{array}$ & $\begin{array}{l}\theta \\
\left({ }^{\circ} \mathrm{C}\right)\end{array}$ & $\mathrm{S}$ & 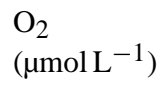 & $\begin{array}{l}\mathrm{PO}_{4} \\
(\mu \mathrm{mol} \mathrm{L}-1)\end{array}$ & $\begin{array}{l}\mathrm{NO}_{3} \\
(\mu \mathrm{mol} \mathrm{L}-1)\end{array}$ & $\begin{array}{l}\mathrm{Si} \\
(\mu \mathrm{mol} \mathrm{L}-1)\end{array}$ \\
\hline StrMW & 19.0 & 36.70 & 100 & 0.16 & 2.0 & 2.0 \\
\hline $\mathrm{NACW}_{\mathrm{u}}$ & 18.0 & 36.45 & 250 & 0.15 & 2.0 & 2.0 \\
\hline $\mathrm{H}$ & 12.2 & 35.60 & 230 & 0.70 & 12.0 & 4.5 \\
\hline $\mathrm{NACW}_{1}$ & 8.8 & 35.15 & 195 & 1.20 & 20.0 & 12.0 \\
\hline MW & 13.2 & 37.10 & 170 & 1.00 & 16.0 & 7.0 \\
\hline mAAIW & 6.5 & 34.90 & 110 & 2.10 & 32.0 & 23.0 \\
\hline SAIW & 5.6 & 34.70 & 280 & 1.00 & 15.0 & 6.0 \\
\hline LSW & 3.4 & 34.89 & 295 & 1.10 & 17.0 & 12.0 \\
\hline $\mathrm{NADW}_{\mathrm{u}}$ & 2.5 & 34.94 & 250 & 1.30 & 20.0 & 35.0 \\
\hline Weight & 24 & 22 & 7 & 2 & 7 & 1 \\
\hline
\end{tabular}

$\theta$-S diagrams, connecting two $\theta-\mathrm{S}$ points (Fig. 2a): west of the Mid-Atlantic Ridge (MAR) (the western NACW WNACW) - the deep point is $\left[7.0-8.5^{\circ} \mathrm{C} ; 35.0-35.1\right]$ and the near-surface point is $\left[18.0-19.0^{\circ} \mathrm{C} ; 36.4-36.6\right]$, and east of the Mid-Atlantic Ridge (the eastern NACW - ENACW) the deep point is $\left[8.5-9.5^{\circ} \mathrm{C} ; 35.2-35.3\right]$ and the near-surface point is [18.0-19.0 $\left.{ }^{\circ} \mathrm{C} ; 36.5-36.7\right]$ (Harvey and Arhan, 1988; Pollard et al., 1996). WNACW consists of $13^{\circ} \mathrm{C}$ mode water (with temperature around $13^{\circ} \mathrm{C}$ ) formed at the frontal zone of the North Atlantic Current northwest of the Azores Islands, between 45 and $50^{\circ} \mathrm{N}$ (McCartney, 1982; Paillet and Arhan 1996b), and $18^{\circ} \mathrm{C}$ mode water formed at the Gulf Stream frontal zone (Harvey and Arhan, 1988). The modes of WNACW enter into the region of interest, advected by surface circulation patterns across the Mid-Atlantic Ridge (Pollard and Pu, 1985; Harvey and Arhan, 1988). ENACW occupies the same depth range as WNACW, but the former is on average 0.1 more saline for the same temperature values (van Aken, 2001). The lower ENACW, also referred to as the polar ENACW $\left(\mathrm{ENACW}_{\mathrm{p}}\right)$, is formed by subduction at a sharply deepening winter pycnocline at the southwestern edge of the Bay of Biscay $\left(40-50^{\circ} \mathrm{N}, 20^{\circ} \mathrm{W}\right)$, while the upper ENAWC, also referred to as the tropical ENACW $\left(\right.$ ENACW $\left._{\mathrm{t}}\right)$, is formed in a westward re-circulation of the Azores Current near the Iberian Peninsula (Pérez et al., 1993; Pollard et al. 1996). There are indications that some fraction of the upper ENAWC is also formed near Madeira Island sometimes called the Madeira Mode Water (Siedler et al., 1987; Pingree et al., 1999; New et al., 2001). The lowest fraction of NACW represents a mixture of the lower WNACW or ENACW $_{\mathrm{p}}$ with deeper water masses.

In the study region, most of the upper NACW between 200 and $400 \mathrm{~m}$ is represented by the upper WNACW, transported in the area from the west, and $\mathrm{ENACW}_{\mathrm{t}}$ is observed only over a very limited area close to its formation region near the Iberian Peninsula (Pollard and Pu, 1985; Paillet and Arhan, 1996a, b). The main source of the deeper NACW, north of the Azores Current and as far east as the MAR, is ENACW $_{\text {p }}$ (Pérez et al., 1993; Pallet and Arhan, 1996a,b; van Aken, 2001).

The upper NACW in the southwestern part of the study region is affected by the subtropical mode water (StrMW). StrMW is characterised by elevated temperature and salinity (Table 2) and comparatively low oxygen and high nutrient contents (Krémeur et al., 2009). StrMW is formed south of the Gulf Stream as a result of an intense surface heat loss during winter storms (Mazé and Marshall, 2011).

In $\theta$-S diagrams, NACW lines (either WNACW or ENACW) are slightly curved and can be better approximated with two sections of a broken line. To account for this feature, in water mass analysis an additional water type $(\mathrm{H}$, Table 2$)$ is introduced, the characteristics of which slightly differ depending on whether WNACW or ENACW are being considered (Pérez et al., 1998; Alvaréz et al., 2004; Barbero et al., 2010). It is placed at the maximum curvature of the $\theta$-S line, the junction between the upper and the lower NACW. In the study region this point is found at around $500 \mathrm{~m}$.

\subsection{Intermediate water masses: MW, SAIW and AAIW}

At the intermediate water levels (700-1500 m depth) a mixture of the Mediterranean Water (MW), the Subarctic Intermediate Water (SAIW) and the Antarctic Intermediate Water (AAIW) is observed (Table 2). SAIW is a relatively cold and fresh water mass with high oxygen contents, formed west of the MAR at the northern branch of the North Atlantic Current $\left(50-54^{\circ} \mathrm{N}\right)$. A part of the SAIW (with temperature 4$7^{\circ} \mathrm{C}$ ) is advected northwest between 45 and $55^{\circ} \mathrm{N}$, with the northern branch of the North Atlantic Current. Another part of the SAIW (with temperature 9-10 ${ }^{\circ} \mathrm{C}$ ) spreads southeast, along both sides of the MAR, down to $40-45^{\circ} \mathrm{N}$. On its way it gradually mixes with NACW and the Labrador Sea Water and deepens to $700-1000 \mathrm{~m}$ at its southern limit (McCartney and Talley, 1982; Harvey and Arhan, 1988; Tsuchiya, 1989; 

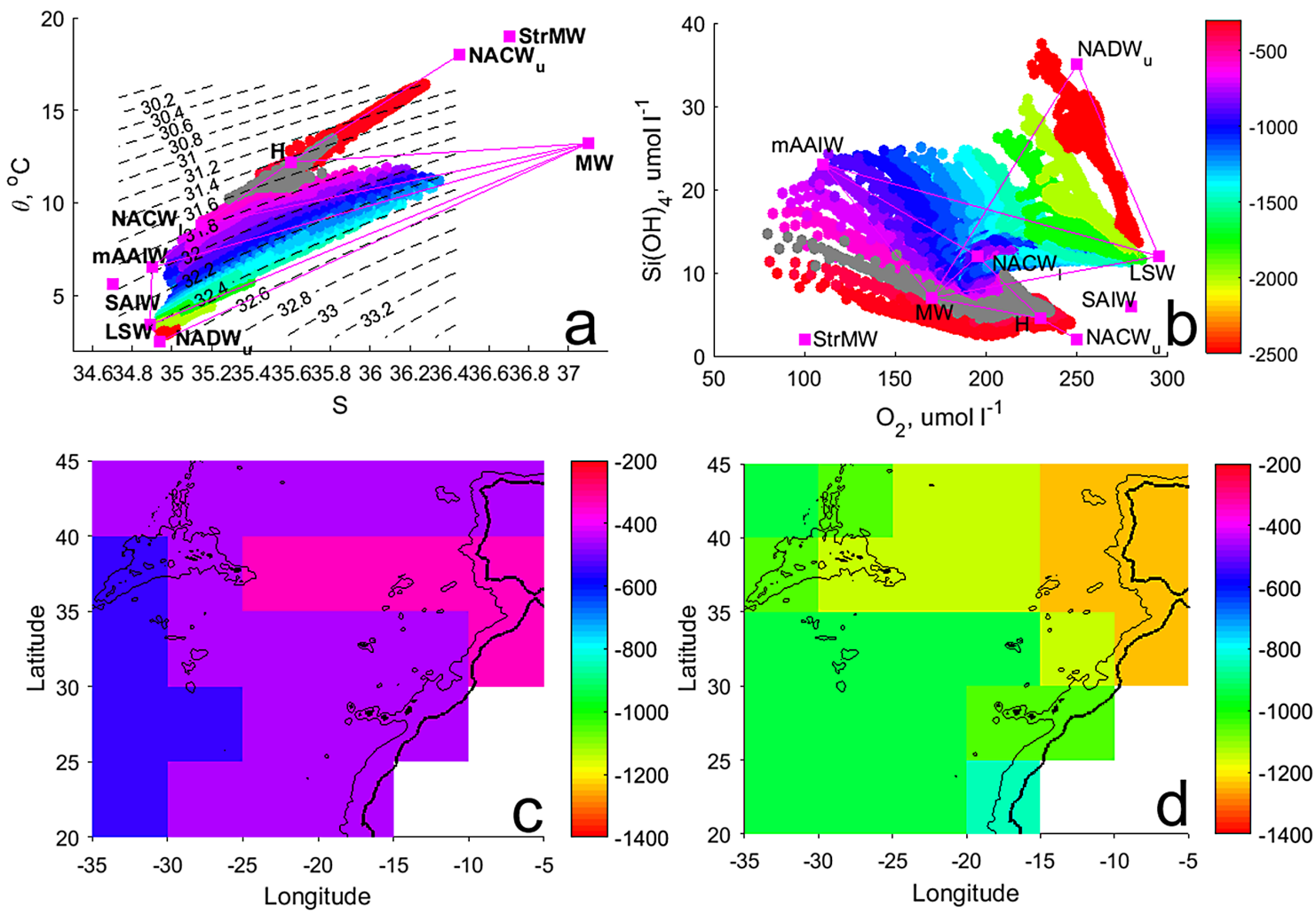

Figure 2. (a) $\theta$-S diagram; (b) $\mathrm{Si}-\mathrm{O}_{2}$ diagram; (c) depth of the lower limit of layer 1 (m); (d) depth of the lower limit of layer 2 (m). Colour scale in panels (a) and (b) presents depth of the sample. The isopycnals in panel (a) are referenced to $1000 \mathrm{~m}\left(\sigma_{1}\right)$.

Arhan, 1990). Some traces of SAIW are found to spread east to $20-25^{\circ} \mathrm{W}$, (Arhan, 1990; Arhan et al., 1994) or to $10^{\circ} \mathrm{W}$, (McCartney and Talley, 1982). SAIW forms a frontal zone with the main body of the Mediterranean Water from the eastern tip of the Azores rise to the Bay of Biscay (Arhan et al. 1994). AAIW is found in the Atlantic and is formed both at the Antarctic Polar Front and the neighbouring Scotia Sea (Schmitz, 1996; Tomczak and Godfrey, 2003). This mass spreads north with the Malvinas Current and further with the currents of the South Atlantic subtropical gyre and the equatorial current system. In the North Atlantic AAIW is observed between 700 and $900 \mathrm{~m}$ and is characterised by a salinity minimum, an oxygen minimum and a silicate maximum (Schmitz, 1996). Its characteristics in the North Atlantic are already quite different from the ones in the generation region (temperature of $2.2^{\circ} \mathrm{C}$ and salinity of 33.8), and it is called here the modified AAIW (mAAIW; in some works also denoted as the AA - Pérez et al., 1998, 2001; Alvaréz et al., 2004). mAAIW can be traced as a salinity minimum up to $25-26^{\circ} \mathrm{N}$ (Tsuchiya et al., 1992), but using nutrient anomalies, along the African coast it can be traced up to $30-32^{\circ} \mathrm{N}$ (Machin et al., 2006; Machín and Pelegrí, 2009). Some traces of mAAIW are detected as far north as the Gulf of Cádiz (Louarn and Morin, 2011), but those are generally very weak (Pastor et al., 2012). Another portion of mAAIW spreads along the American continental margin with the Caribbean Current, the Gulf Stream and the North Atlantic Current, entering the study region from the northwest (Tsuchiya, 1989). It enters the NE Atlantic basin already much more diluted than mAAIW at the African margin, but can still be detected as a silica maximum and a weak salinity-oxygen minimum just above MW, at 500-800 m depth (Tsuchiya et al., 1992; Arhan et al., 1994). The MW is formed from the outflow in the Atlantic of the anomalously saline and warm Mediterranean Sea water. The MW has low oxygen and nutrient content. From the Gibraltar Strait, the MW first spreads as the concentrated Mediterranean undercurrent (MUC), trapped by the continental slope of the Iberian Peninsula. Over the first $100 \mathrm{~km}$ the MUC deepens from around $100 \mathrm{~m}$ just off the Gibraltar Strait to its neutral buoyancy level at 1200-1300 m depth (Baringer and Price, 1997). The rapid sinking is accompanied by a strong mixing with the ambient NACW and the upper North Atlantic Deep Water (NADW), as well as by the entrainment of both. The entrainment increases the MUC transport to 3-5 times its initial value. Therefore, the original Mediterranean Sea water properties are strongly modified in the Atlantic MW (Price et al., 1993; van Aken, 2000b; Barbosa Aguiar et al., 2014). The deeper MW fractions mostly leave the continental slope south of Estremadura Promontory $\left(39^{\circ} \mathrm{N}\right)$ to spread west and southwest, while the lighter 
fractions follow the continental margin further north to join the North Atlantic Current northwest of the Irish continental slope (Daniault et al., 1994; Mazé et al., 1997; Iorga and Lozier, 1999a).

After leaving the continental margin, MW mostly spreads west to the Azores rise. This water sometimes is called the "pure" MW. Its core is at $800-1000 \mathrm{~m}$. The lower fractions of MW, presumably a mixture with the North Atlantic Deep Water, preferably spread westward south of the Azores Current at 1000-1200 m (Harvey and Arhan, 1988; Iorga and Lozier, 1999a; van Aken, 2000b). The MW influence is most pronounced between 700 and $1500 \mathrm{~m}$, but some weak MW influence is detected from $500 \mathrm{~m}$ down to $3000 \mathrm{~m}$ depth (Tsuchiya et al., 1992; Arhan et al., 1994).

\subsection{Deep water masses: LSW and NADW}

The Labrador Sea Water (LSW) is formed by deep convection in the Labrador Sea. It is a cold and fresh water mass, and it is characterised by a high oxygen content (Table 2). The LSW penetrates the NE Atlantic crossing the MAR through the Charlie-Gibbs fracture zone (Talley and McCartney, 1982; Straneo et al., 2003). The majority of the LSW spreads south along the eastern slope of the MAR at the speed of the order of $1 \mathrm{~cm} \mathrm{~s}^{-1}$, skirting the eastern slope of the Azores rise at 1200-2500 m (Harvey and Arhan, 1988; Paillet et al., 1998; Bower et al., 2002a). A temperaturesalinity front, which separates the LSW from the MW, is approximately aligned with that between the MW and the SAIW (Paillet et al., 1998). The influence of the LSW decreases south and southwest and thus no LSW is expected in the southeastern part of the study region.

The NADW is detected within the depth range between 1000 and $4000 \mathrm{~m}$ across the whole Atlantic. There are several types of NADW. The main ones are the upper NADW $\left(\mathrm{NADW}_{\mathrm{u}}\right)$, or the Iceland-Scotland Overflow Water (ISOW), and the lower NADW, or the Low Deep Water (LDW). The core of the cold oxygenated NADW is formed as a result of deep convection in the Greenland Sea. It spreads south through the Denmark Strait west of Iceland, as well as east of Iceland (Hansen and Osterhus, 2000). Southeast of Iceland, over the relatively shallow Faeroe-Iceland and FaeroeScotland sills, NADW strongly mixes with the water of the North Atlantic Current forming $\mathrm{NADW}_{\mathrm{u}}$ (Tsuchiya et al., 1992). It is slightly colder, more saline and richer in silica than LSW. In the subtropical NE Atlantic it is observed from about 2500 to $3000 \mathrm{~m}$ and below, and mostly enters the study region from the north, although it may also enter from the west and southwest (Harvey and Arhan, 1988; Schmitz, 1996; Brix and Gerdes, 2003).

West of Iceland, NADW enters the western North Atlantic basin and mixes with LSW, forming the lower NADW (Harvey and Arhan, 1988). Some of the lower NADW enters the NE Atlantic through the Charlie-Gibbs fracture zone, but the majority of it is thought to enter the NE Atlantic basin at around $10^{\circ} \mathrm{N}$ and to spread north below $3500 \mathrm{~m}$ together with the Antarctic Bottom Water (AABW). The AABW is formed at the Antarctic continental slope (Orsi et al., 2001). Diapycnal mixing with the AABW modifies the deeper fraction of the lower NADW (van Aken, 2000a).

\section{Data and methods}

\subsection{The data sets}

Temperature and salinity, the principal parameters for water mass identification in the OMP analysis, were downloaded from the regional MEDTRANS climatology which has spatial resolution of $30 \mathrm{~km} \times 30 \mathrm{~km} \times 25 \mathrm{~m}$ (http: //www.mare-centre.pt/en/research/medtrans-data). Nutrients (nitrate, phosphate and silicate) and oxygen are not available in the MEDTRANS climatology and were downloaded from the World Ocean Atlas database (WOA13, http://www. nodc.noaa.gov/OC5/woa13). Both the MEDTRANS and the WOA13 climatologies are based on the National Oceanographic Data Center (NODC) data set and use Barnes' Optimum Interpolation analysis (Barnes, 1964) for gridding, but the MEDTRANS climatology uses gridding along the neutral density surfaces instead of fixed z-levels in the WOA13. This has an advantage over WOA13 in the representation of temperature and salinity distributions in the areas with sharp horizontal gradients of water characteristics: in particular, of the Mediterranean undercurrent (see for further details Bashmachnikov et al., 2015a). The hydrological and nutrient data are merged into the common grid with a horizontal resolution of $30 \mathrm{~km}$ and a vertical resolution of $25 \mathrm{~m}$. From the temperature-salinity distributions, the neutral density surfaces are computed. Those represent a generalisation of isopycnic surfaces referenced to the local depth level (McDougall, 1987; Jackett and McDougall, 1997).

The pathways of water transport are derived using the resultant spatial variations of the contents of each source water type. The resulting pathway patterns are further compared to the circulation patterns, derived from RAFOS and Argo floats, giving additional regional details to the previous larger scale studies (Bower et al., 2002a; Ollitrault and Colin de Verdière, 2014; Carracedo et al., 2014).

The RAFOS float data were downloaded from the World Ocean Circulation Experiment (WOCE) Subsurface Float Data Assembly Center (http://wfdac.whoi.edu/). The data set of 353 floats covers depth intervals from 400 to $1700 \mathrm{~m}$ and the time period from 1982 to 2002 (MODE Group, 1978; Rossby et al., 1985; Davis et al., 1996). The typical sampling period is from $6 \mathrm{~h}$ to a day, and the overall duration of the observations is 6700 float months.

The Argo float data were obtained from the Coriolis operational data centre (Coriolis, ftp://ftp.ifremer.fr). A data set of 242 Argo floats covers the same depth range as above within the time period from 1999 to 2013. The typical sampling pe- 
riod is $10-15$ days. The overall duration of the observations is 6560 float months.

From the float positions, Eulerian currents are computed, gridded to a $1^{\circ} \times 1^{\circ}$ regular grid for the selected depth levels (details are presented in Appendix 1).

The bottom topography is obtained from the General Bathymetric Chart of the Oceans (GEBCO)'s $1^{\prime} \times 1^{\prime}$ bathymetry data (http://www.gebco.net/data_and_products/ gridded_bathymetry-data/).

\subsection{The optimum multiparameter analysis set-up}

The quantitative estimate of relative contributions of the main source water types in the study region is obtained with the OMP analysis (Tomczak, 1981; Mackas et al. 1987; Tomczak and Large, 1989). The OMP analysis assumes that, below the upper mixed layer, all water characteristics vary only as a result of mixing between the interacting source water types, and that the mixing of different water characteristics goes at the same rate. Contributions from the predefined set of source water types are determined in each of the grid points by inverting the system of linear equations. The method decomposes each of the observed water properties into a combination of the known corresponding characteristics of the source water types, multiplied by the unknown contributions of the latter (Eq. 1). The classical OMP analysis considers all water properties to behave like passive tracers. In this version of the method, the maximum number of the simultaneously resolved source water types is limited by the number of water properties measured in situ. The method has been successfully applied to study spatially limited regional distributions of water types, mixing and circulation patterns (e.g. Klein and Tomczak, 1994; Gasparin et al., 2014). Applied to ocean-basin scales, the non-conservative variation of nutrients due to biochemical processes in the water column (the water mass aging) has to be taken into account. The unknown rates of remineralisation of nutrients due to oxidation are then incorporated as additional variables (Karstensen and Tomczak, 1997; Poole and Tomczak, 1999). An assumption of the equal rate of remineralisation of all the nutrients and of the proportional decrease of oxygen in the process of oxidation of the subducted detritus allows one to reduce the number of added biochemical unknowns down to one (Karstensen and Tomczak, 1997; Poole and Tomczak, 1999). Due to the predominantly biological origin of the detritus in the open ocean, the rates of nitrogen, oxygen, etc., variations due to remineralisation can be converted into phosphate variation using their stochiometric ratios in phytoplankton - the Redfield ratios (Redfield et al., 1963). This methodology is known as the extended OMP analysis (Karstensen and Tomczak, 1997), and has been applied in this study. The code is available from http://omp.geomar.de. The water characteristics used in the extended OMP analysis are potential temperature $(\theta)$, salinity $(S)$, oxygen $\left(\mathrm{O}_{2}\right)$, nitrate $\left(\mathrm{NO}_{3}^{-}\right)$, phosphate $\left(\mathrm{PO}_{4}^{3-}\right)$ and silicate $\left(\mathrm{Si}(\mathrm{OH})_{4}\right.$, hence- forth labelled as $\mathrm{Si}$ ), and the system of equations is

$$
\begin{aligned}
& x_{1} \theta_{1}+x_{2} \theta_{2}+x_{3} \theta_{3}+x_{4} \theta_{4}+x_{5} \theta_{5}=\theta_{\mathrm{obs}}+R_{\theta} \\
& x_{1} S_{1}+x_{2} S_{2}+x_{3} S_{3}+x_{4} S_{4}+x_{5} S_{5}=S_{\mathrm{obs}}+R_{S} \\
& x_{1}\left[\mathrm{PO}_{4}\right]_{1}+x_{2}\left[\mathrm{PO}_{4}\right]_{2}+x_{3}\left[\mathrm{PO}_{4}\right]_{3}+x_{4}\left[\mathrm{PO}_{4}\right]_{4} \\
& \quad+x_{5}\left[\mathrm{PO}_{4}\right]_{5}+\Delta \mathrm{P}=\left[\mathrm{PO}_{4}\right]_{\mathrm{obs}}+R_{\mathrm{PO}_{4}} \\
& x_{1}\left[\mathrm{NO}_{3}\right]_{1}+x_{2}\left[\mathrm{NO}_{3}\right]_{2}+x_{3}\left[\mathrm{NO}_{3}\right]_{3}+x_{4}\left[\mathrm{NO}_{3}\right]_{4} \\
& \quad+x_{5}\left[\mathrm{NO}_{3}\right]_{5}+r_{\mathrm{N} / \mathrm{P} \Delta} \Delta \mathrm{P}=\left[\mathrm{NO}_{3}\right]_{\mathrm{obs}}+R_{\mathrm{NO}_{3}} \\
& x_{1}\left[\mathrm{O}_{2}\right]_{1}+x_{2}\left[\mathrm{O}_{2}\right]_{2}+x_{3}\left[\mathrm{O}_{2}\right]_{3}+x_{4}\left[\mathrm{O}_{2}\right]_{4}+x_{5}\left[\mathrm{O}_{2}\right]_{5} \\
& \quad-r_{\mathrm{O} / \mathrm{P} \Delta} \Delta \mathrm{P}=\left[\mathrm{O}_{2}\right]_{\mathrm{obs}}+R_{\mathrm{O}_{2}} \\
& x_{1}[\mathrm{Si}]_{1}+x_{2}[\mathrm{Si}]_{2}+x_{3}[\mathrm{Si}]_{3}+x_{4}[\mathrm{Si}]_{4}+x_{5}[\mathrm{Si}]_{5} \\
& \quad=[\mathrm{Si}]_{\mathrm{obs}}+R_{\mathrm{Si}} \\
& x_{1}+x_{2}+x_{3}+x_{4}+x_{5}=1+R_{\Sigma} .
\end{aligned}
$$

On the left-hand side of the Eq. (1), the known parameters are the characteristics of source water types $\left(\theta_{1}, \theta_{2}, \ldots, S_{1}\right.$, $S_{2}, \ldots,\left[\mathrm{Si}_{1},[\mathrm{Si}]_{2}, \ldots,[\mathrm{Si}]_{5}\right)$ and the biogeochemical Redfield ratios $(r)$ of the corresponding non-conservative parameters to $\left[\mathrm{PO}_{4}\right]$. In order to make the units of different parameters commensurable, a normalisation of the source water type matrix is performed (Karstensen and Tomczak, 1997). The unknown parameters are the source water type contributions $x_{1}, \ldots, x_{5}$ and the phosphate remineralisation rate $\Delta P$. The right-hand side represents the observed values of each parameter $\left(\theta_{\mathrm{obs}}, \ldots,[\mathrm{Si}]_{\mathrm{obs}}\right)$ and their respective residuals $\left(R_{\theta}, \ldots, R_{\mathrm{Si}}\right)$. The square brackets denote nutrient concentrations and are henceforth omitted. Following some of the previous studies, $\mathrm{Si}$ is considered to be a conservative tracer (van Aken, 2000a; Alvaréz et al., 2004). This is because the remineralisation processes are of low intensity, different from those of other nutrients. Moreover, the stochiometric ratios in phytoplankton of $\mathrm{Si}$ to $\mathrm{O}_{2}$ and to other nutrients are regional and depth dependent (van Aken, 2000a).

Two additional realistic constraints are imposed on the system of Eq. (1) the contributions from all the source water types add up to $100 \%$ within the error $R_{\sum}$ and all the contributions $x_{1}, \ldots, x_{5}$ are non-negative. A non-trivial value of $R_{\sum}$ requires the system to be over-determined and the seven equations of the system of Eq. (1) allow for simultaneous analysis of the contributions of up to five different source water types.

Results of the OMP analysis critically depend on the choice of the dominating source water types. The preliminary choice of five main source water types, affecting a certain range of water levels in each of the $5^{\circ} \times 5^{\circ}$ squares, is based on the previous studies, described in the introduction (Tsuchiya et al., 1992; Pérez et al., 1998; Poole and Tomczak, 1999; van Aken, 2000a, b, 2001; Pérez et al., 2001; Cabeçadas et al., 2002; Alvaréz et al., 2004; Barbero et al., 2010; Louarn and Morin, 2011).

The number of water types in the OMP is limited by the number of variables observed in situ (Eq. 1). To uniformly resolve the mid-depth source water types of interest, the western and eastern fractions of NACW are clamped together into the upper NACW $\left(\mathrm{NACW}_{\mathrm{u}}\right)$, North Atlantic Central Water, the maximum inflection point $(\mathrm{H})$ and the lower 
NACW $\left(\mathrm{NACW}_{1}\right)$. StrMW is treated separately due to its comparatively vast distribution in the southwestern part of the study region and to its very particular nutrient concentrations (Table 2 and Fig. 2a-b). The resulting characteristics of $\mathrm{NACW}_{\mathrm{u}}, \mathrm{H}$ and $\mathrm{NACW}_{1}$ are taken within the known limits of the corresponding fractions of WNACW and ENACW, such that the mixing triangles, formed with the water types above in each of the parameter spaces $\left(\theta-\mathrm{S}, \theta-\mathrm{O}_{2}, \theta-\mathrm{NO}_{3}\right.$, $\theta$-Si, etc.), tightly surround all the observed data points in all parts of the study region (Fig. 2a-b). As a result, the characteristics of $\mathrm{NACW}_{\mathrm{u}}$ and of $\mathrm{H}$ (Table 2) are taken close to the mean of the corresponding fractions of WNACW and ENACW, as both influences the upper and mid-thermocline in the study region. The final characteristics of $\mathrm{NACW}_{1}(\mathrm{Ta}-$ ble 2) are taken close to those of $\mathrm{ENACW}_{1}$, as this fraction is known to strongly dominate most of the lower main thermocline study region (Pollard et al., 1996).

The extremely low values of oxygen at around $500 \mathrm{~m}$ depth (Fig. 2b) are a result of the influence of the Guinea Dome Water. It is formed near the Cape Verde Islands and is advected north along the African continental margin (Stramma et al., 2008; Peña-Izquierdo et al., 2015). This source water type has temperature and salinity values close to those in $\mathrm{NACW}_{1}$, but it is characterised by an anomalously low oxygen $\left(70 \mu \mathrm{mol} \mathrm{L}^{-1}\right)$ and a relatively high silicate $\left(14 \mu \mathrm{mol} \mathrm{L}^{-1}\right)$ concentration. In spite of this, the Guinea Dome Water is not included in the analysis, since we would not able to uniformly resolve other water types across the study region, and since its influence in the region is comparatively low being limited to the mid-thermocline in its south-easternmost part. In the OMP results for the southeasternmost part of the study region, the Guinea Dome Water content is partly incorporated into the derived contents of mAAIW and StrMW.

Even after those simplifications, taken over the entire water column, the number of the source water types of possible importance often exceeds the limit of five. This allows for segmentation of the water columns into three layers: the upper main thermocline layer (layer 1), the intermediate layer (layer 2) and the deep layer (layer 3). Within each of the layers a particular set of water types is used. The vertical limits of the layers are defined again from analysis of the mixing triangles of the main of source water types in each of the $5^{\circ} \times 5^{\circ}$ areas. They represent the depths of the intersections of the lines - the sides of the mixing triangles - with the curves of vertical variation of the corresponding water properties observed in $\theta$-S, $\theta-\mathrm{O}_{2}, \theta-\mathrm{NO}_{3}, \theta$-Si, etc. diagrams (see examples in Fig. 2a-b). It is clear from the plot that some of the source water types are nearly undistinguishable in $\theta$-S diagrams, but are well differentiated in $\mathrm{Si}-\mathrm{O}_{2}$ diagrams (as is also the case for StrMW and $\mathrm{NACW}_{\mathrm{u}}$, SAIW and mAAIW, LSW and NADW ${ }_{u}$ ). This demonstrates the importance of adding nutrients to the OMP analysis.

The results of the vertical layering are shown in Fig. 2c$d$. The upper boundary of layer 1 is located at the base of the winter mixed layer and the depth of its lower boundary varies from 350 to $550 \mathrm{~m}$ (Fig. 2c). The source water types of layer 1 are StrMW, $\mathrm{NACW}_{\mathrm{u}}, \mathrm{H}, \mathrm{NACW}_{1}$ and MW (MW influences layer 1 in the Gulf of Cádiz). Layer 2 extends from the lower boundary of layer 1 to about $1200-1300 \mathrm{~m}$ in the northeastern part of the region and to $900-1000 \mathrm{~m}$ at its southwestern part (Fig. 2d). The source water types of layer 2 are $\mathrm{NACW}_{1}, \mathrm{MW}, \mathrm{mAAIW}, \mathrm{SAIW}$ and LSW. Layer 3 extends from the lower boundary of layer 2 to the maximum analysed depth of $2000 \mathrm{~m}$. The source water types of layer 3 are $\mathrm{NACW}_{1}, \mathrm{MW}, \mathrm{mAAIW}, \mathrm{LSW}$ and $\mathrm{NADW}_{\mathrm{u}}$.

The characteristics of the source water types are taken not from their areas of origin, but at their entry in the study region. Thus, transformation of their properties on their way to the region of interest due to mixing with other source water types, not accounted for in this study, does not affect the results of the analysis. This is especially relevant for the source water types formed far away from the study region, as is the case for mAAIW.

The characteristics of the source water types used (Table 2) are based on the works by Karstensen and Tomczak (1997), Pérez et al. (1998, 2001), Poole and Tomczak (1999), van Aken (2000a, b), van Aken (2001), Cabeçadas et al. (2002), Álvarez et al. (2004), Barbero et al. (2010), Louarn and Morin (2011) and Carracedo et al. (2014). In this table mAAIW is defined as the characteristics of AAIW near the Canary Islands (Tsuchiya et al., 1992; Pérez et al., 1998, 2001; Álvarez et al., 2004), MW as the southern continental slope of the Iberian Peninsula at $7^{\circ} \mathrm{W}$, (i.e. where the lower core of the MUC stabilises between 800 and $1000 \mathrm{~m}$ depth, Baringer and Price, 1997; Bower et al., 2002b; Louarn and Morin, 2011), and LSW and NADW as they enter the study region from the north (Pérez et al., 1998, 2001; van Aken, 2000a, b; Álvarez et al., 2004; Barbero et al., 2010). For SAIW and the fractions of NACW, their properties in the place of origin are used, since both water types originate in the immediate vicinity of the boundaries of the study region.

Stochiometric Redfield ratios slightly vary across the ocean and with depth (Anderson and Sarmiento, 1994; Dafner et al., 2003; Pérez et al., 1998, 2001). In this study $\mathrm{O}_{2}: \mathrm{NO}_{3}: \mathrm{PO}_{4}=150: 16: 1$ is used as a reasonable balance between the estimates from the different parts of the Atlantic region, presented in the studies above.

In situ observations of different water characteristics, used for the OMP, are not equally reliable and representative. Therefore, different equations of the system of Eq. (1) should not equally influence the results. Differences in instrumental accuracy of in situ measurements of different parameters, different range and rate of their time variation, different accuracy in definition of Redfield ratios for the nonconservative parameters, are used for weighting equations in system of Eq. (1). The weights used in this study (Table 2) are adopted from the works by Tomczak and Large (1989), Álvarez et al. (2004), Barbero et al. (2010) and Louarn and Morin (2011). The lowest weight in our analysis is attributed 


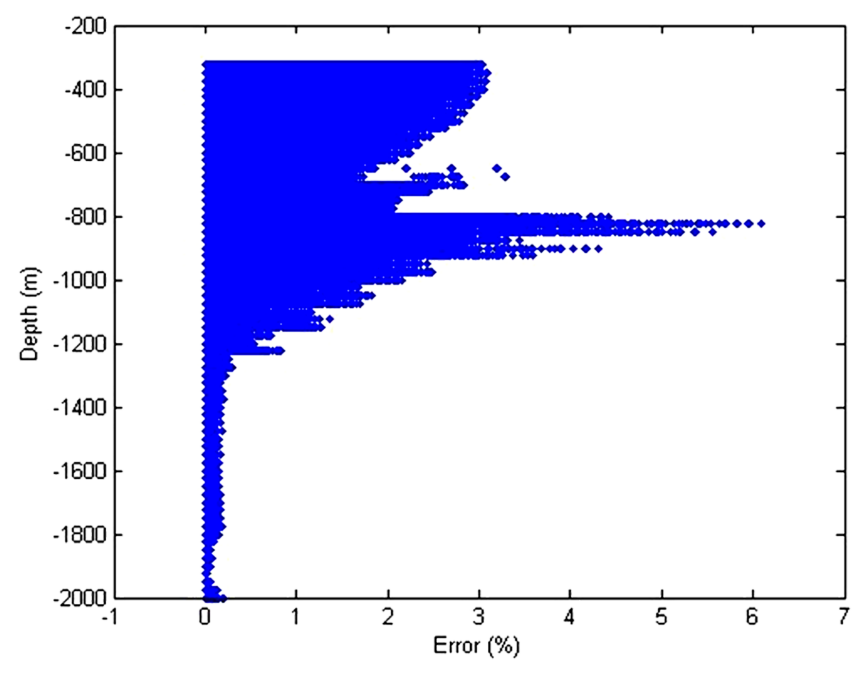

Figure 3. OMP mass conservation residuals $\left(R_{\Sigma}\right)$. The residuals represent the difference between the theoretical value obtained with the result of the OMP analysis and the observed data.

to silicate, since its biochemical degradation is not considered.

\subsection{The accuracy of the OMP analysis}

We estimate the minimum source water type contents detectable under the selected configuration, as well as of the robustness of the results. Two different estimates of the OMP errors are considered: (i) the formal error of the fit, equal to the mass conservation residual $R_{\Sigma}$, and (ii) sensitivity of the results to variations of characteristics of the source water types.

The values of $R_{\Sigma}$ over the study region are presented in Fig. 3 as a function of depth. The errors are mostly below $3 \%$ and do not exceed $6 \%$. This suggests an adequate choice of the source water types and of the layer limits (Karstensen and Tomczak, 1997). The maximum errors are concentrated at the transition between the sets of source water types of layers 1 and 2. Here, the number of different source water types affecting a water parcel often exceeds the limit of five.

In the sensitivity test, the OMP analysis is repeated for the same sets of the source water types, but their characteristics vary within some predefined limits. These limits are taken equal to the standard deviation between the source water type characteristics, taken from different regional studies: $\pm 0.2{ }^{\circ} \mathrm{C}$ in temperature, \pm 0.05 in salinity, $\pm 20 \mu \mathrm{mol} \mathrm{L}^{-1}$ in oxygen, $\pm 0.1 \mu \mathrm{mol} \mathrm{L}^{-1}$ in phosphate, $\pm 1.5 \mu \mathrm{mol} \mathrm{L}^{-1}$ in nitrate and $\pm 2.0 \mu \mathrm{mol} \mathrm{L}^{-1}$ in silicate (Karstensen and Tomczak, 1997; Pérez et al., 1998, 2001; Poole and Tomczak, 1999; van Aken, 2000a,b, 2001; Cabeçadas et al., 2002; Álvarez et al., 2004; Barbero et al., 2010; Louarn and Morin, 2011; Carracedo et al., 2014).

The sensitivity analysis reveals that LSW and $\mathrm{NADW}_{\mathrm{u}}$ may inter-exchange significant fractions of their percentages,
Table 3. Mean error and respective standard deviation (SD) of the results of OMP analysis regarding the sensitivity experiments. The upper error limit corresponds to the value, which is above $99 \%$ of the errors at all grid points and at all depths levels.

\begin{tabular}{lrr}
\hline Water type & $\begin{array}{r}\text { Mean error } \\
\pm S D(\%)\end{array}$ & $\begin{array}{r}\text { Upper error } \\
\text { limit }(\%)\end{array}$ \\
\hline NACW & $5 \pm 1$ & 9 \\
SAIW & $9 \pm 1$ & 13 \\
MW & $2 \pm 0$ & 3 \\
mAAIW & $5 \pm 1$ & 7 \\
LSW $^{\text {NADH }}$ & $6 \pm 1$ & 8 \\
\hline
\end{tabular}

when variations of source water type characteristics are close to the limiting values above. At some depths, this also occurs for different fractions of NACW. On the other hand, the errors of the sum of percentages of LSW and NADW sum of percentages of all the fractions of NACW, are within the $10 \%$ limit (Table 3). Therefore, for further analysis we consider the sum of the percentages of LSW and NADW NADW. For the same reason, the resulting concentrations of StrMW, $\mathrm{NACW}_{\mathrm{u}}, \mathrm{H}$ and $\mathrm{NACW}_{1}$ are summed to the NACW. The sensitivity errors, averaged over the study area (Table 3 ) are mostly below $10 \%$, while MW error is below $3 \%$.

Summarising the results above, $10 \%$ of the contents of a given source water type is taken as the upper limit of the OMP analysis error.

\section{Results}

\subsection{Distribution of source water types in the subtropical NE Atlantic}

NACW contents (Fig. 4) decreases from its maximum (90$100 \%$ ) at the upper boundary of layer 1 to $60-100 \%$ at $700-800 \mathrm{~m}$ (Fig. 4a, b) and to $10-20 \%$ already at 900 $1200 \mathrm{~m}$ (Fig. 4c, d). The isolines of equal percentage of NACW are mostly aligned along neutral density surfaces, suggesting along-isopycnal spreading. A significant crossisopycnal deepening of the lower boundary of NACW occurs near the Iberian Peninsula (Fig. 4c). This anomalously strong downwards cross-isopycnal flux is presumably related to the downwards entrainment by the Mediterranean undercurrent during its rapid descend along the northern slope in the Gulf of Cádiz (Baringer and Price, 1997; Barbosa Aguiar et al., 2014), as well as a diapycnal mixing in the extremely weakly stratified mid-depth levels of the Gulf of Cádiz. The deep portion of NACW is observed to spread southwards from the Iberian Peninsula together with the deep fraction of MW (see below Fig. 7b).

SAIW maximum of $45-50 \%$ is observed in the northwestern part in the study region at $800-900 \mathrm{~m}$, from where two maxima extend south along both sides of the MAR (Fig. 5a, 

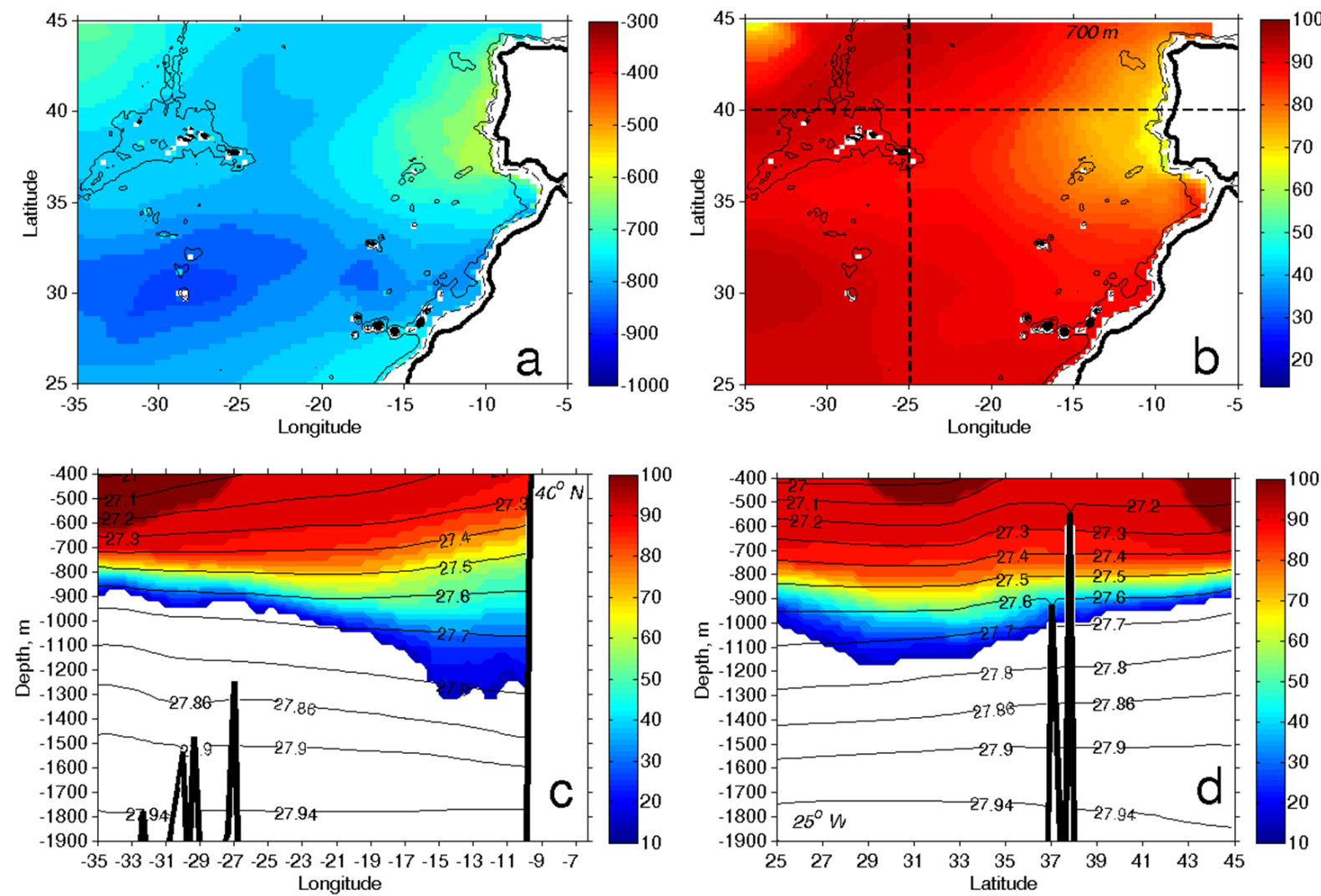

Figure 4. NACW: (a) depth of $50 \%$ of NACW content. (b) NACW content (\%) at $700 \mathrm{~m}$. Isobaths of 500 and $2000 \mathrm{~m}$ are marked in dashed and solid black lines, respectively. Zonal and meridional sections, presented in panels (c) and (d), are marked with dashed black lines. (c) zonal section of NACW content (\%) along $40^{\circ} \mathrm{N}$; (d) meridional section of NACW content (\%) along $25^{\circ} \mathrm{W}$. Solid black lines are neutral density surfaces.

b). East of the MAR the SAIW penetrates as far south as $32^{\circ} \mathrm{N}$ and as far east as the Iberian Peninsula, gradually deepening to 1000 and $1200 \mathrm{~m}$ (Fig. 5a-d). The latter may be due to SAIW advection by weak mid-depth eastwards flows (Iorga and Lozier, 1999a, b; Bower et al., 2002a). SAIW core is found between the neutral density surfaces 27.65 and $27.80 \mathrm{~kg} \mathrm{~m}^{-3}$ (Fig. 5c, d). It deepens southeast with the isopycnals, but there also exists a diapycnal flux, which results in an increase of SAIW core density by about $0.1 \mathrm{~kg} \mathrm{~m}^{-3}$ over $1000 \mathrm{~km}$ distance, from $34-45$ to $33-35^{\circ} \mathrm{N}$ (Fig. 5d). SAIW core becomes denser as its concentration decreases, which may be a result of mixing of SAIW with the denser MW.

MW content reaches its maximum of $65 \%$ at $1200 \mathrm{~m}$ at the southern margin of the Iberian Peninsula (Fig. 6a). Consistent with the previous studies (Daniault et al., 1994; Bashmachnikov et al., 2015a), along the Iberian slope (the MUC) MW maximum gets shallower northwards. Seawards, west of the Iberian margin, MW reaches the highest concentration between 34 and $40^{\circ} \mathrm{N}$, gradually decreasing from 60 50 to $10 \%$ over the MAR (Figs. 6 and 7). In the south, at the latitude of the Canary Islands, MW makes a rather sharp front with mAAIW, although some traces of MW can be detected as far south as $25^{\circ} \mathrm{N}$. MW thickness decreases to the west (Fig. 6c): from about $1000 \mathrm{~m}$ near the Iberian margin and the Gulf of Cádiz (between the neutral density surfaces 27.35 and $27.94 \mathrm{~kg} \mathrm{~m}^{-3}$ ) to $100-200 \mathrm{~m}$ near the MAR (between 27.50 and $27.87 \mathrm{~kg} \mathrm{~m}^{-3}$ ).

Away from the Iberian margin, MW core deepens from $900-1000 \mathrm{~m}$ in the northwest to $1200-1300 \mathrm{~m}$ in the south and the southeast (Fig. 6b). The inclination of isopycnals does not fully explain the depth variation. MW maximum core is found to follow three different neutral density surfaces $\left(27.70,27.75\right.$ and $\left.27.80 \mathrm{~kg} \mathrm{~m}^{-3}\right)$, with abrupt transitions from one surface to another (Figs. $6 \mathrm{c}-\mathrm{d}$ and $7 \mathrm{c}-\mathrm{d}$ ). The positions of those transitions are schematically presented in Fig. $6 \mathrm{~b}$. The areas between the density jumps represent three MW cores: the upper, the main and the lower cores (as compared with the previously detected two MW cores in Harvey and Arhan, 1988). The cores are thought to originate at different parts of the Iberian continental slope (Fig. 6b, d), from where they follow different paths west or southwest, depending on their depth. Fig. $7 \mathrm{a}-\mathrm{b}$ also show that at $800 \mathrm{~m}$ MW 

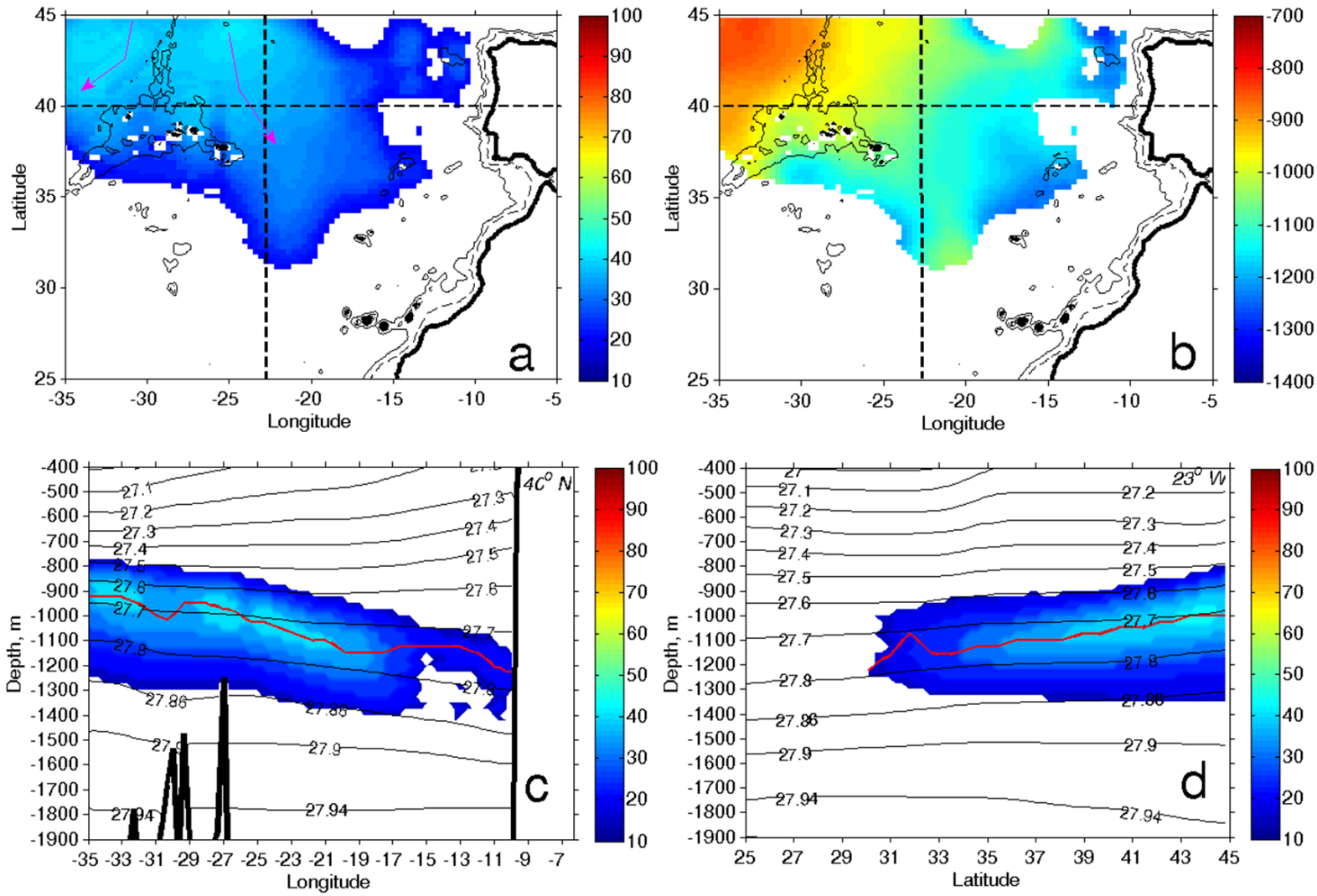

Figure 5. SAIW: (a) maximum percentage in the water column, magenta lines mark suggested pathways of SAIW; (b) depth (m) at which the maximum percentage in the water column is reached. Isobaths of 500 and $2000 \mathrm{~m}$ are marked in dashed and solid black lines, respectively. Zonal and meridional sections, presented in panels (c) and (d), are marked with dashed black lines. (c) zonal section of SAIW content (\%) along $40^{\circ} \mathrm{N}$; (d) meridional section of SAIW content $(\%)$ along $23^{\circ} \mathrm{W}$. Solid black lines are neutral density surfaces. Red line marks the depth of the maximum content of the source water type in the water column.

predominantly spreads west, while at $1500 \mathrm{~m}$ it preferably spreads south-southwest.

The mAAIW content reaches its maximum of around $65 \%$ in the southernmost part of the study region at about $1000 \mathrm{~m}$ (Fig. 8). mAAIW is observed in significant concentration (above $25 \%$ ) only south of the Canary Islands (Fig. 8a), although along the African continental slope east of the islands the northernmost limit of mAAIW reaches $26-32^{\circ} \mathrm{N}$ (Tsuchiya et al., 1992; Machín and Pelegrí, 2009; Pastor et al., 2012). Somewhat higher mAAIW concentration at about $1000-1200 \mathrm{~m}$ also extends further north, up to $30-32^{\circ} \mathrm{N}$, immediately west of the Canary Islands. As mAAIW forms a sharp front with MW, only deeper fractions of mAAIW (below $1200 \mathrm{~m}$ ) penetrate north. Therefore, the core of mAAIW deepens from $1000 \mathrm{~m}\left(27.65 \mathrm{~kg} \mathrm{~m}^{-3}\right)$ at $27^{\circ} \mathrm{N}$ to $1500 \mathrm{~m}$ $\left(27.80 \mathrm{~kg} \mathrm{~m}^{-3}\right)$ at $32^{\circ} \mathrm{N}$, which is contrary to the local inclination of isopycnals (Fig. 8b-c).

A portion of mAAIW enters the study region from the northwest, with the North Atlantic Current (Fig. 8a-d; see also Tsuchiya et al., 1992) at about $900 \mathrm{~m}$ at a low concentration of around $20 \%$. It spreads southeast along the east- ern slope of the MAR at the lower limit of SAIW, following the neutral density surfaces $27.55-27.80 \mathrm{~kg} \mathrm{~m}^{-3}$ (Fig. 8cd). The similar pathways of mAAIW (Fig. 8a) and SAIW (Fig. 5a) in the area of the maximum southwards penetration of both source water types, between 20 and $25^{\circ} \mathrm{W}$, suggest a southwards water transport in this area.

Figure 9 presents the upper fraction of the sum of LSW and NADW $\mathrm{u}_{\mathrm{u}}$. LSW enters the study region from the northwest (Fig. 9a) and dominates the mixture above $1700 \mathrm{~m}$ (Talley and McCartney, 1982; van Aken, 2000a; Bower et al., 2009, 2002a). An interesting feature is the rise of the upper boundary of LSW/NADW $\mathrm{u}_{\mathrm{u}}$ mixture at $33-35^{\circ} \mathrm{N}$, south of the Azores (Fig. 9b). We interpret this as LSW transport across the MAR at the bottom boundary of the Azores Current. LSW/NADW ${ }_{\mathrm{u}}$ mixture substantially deepens under MW (Fig. 9b-d), as MW limits LSW westward penetration (van Aken, 2000a).

Zonal and meridional sections, summarising the areas of significant influence of the source water types (more than $25 \%$ ) are presented in Figs. 10 and 11. NACW content is observed above the neutral density surfaces 27.65 

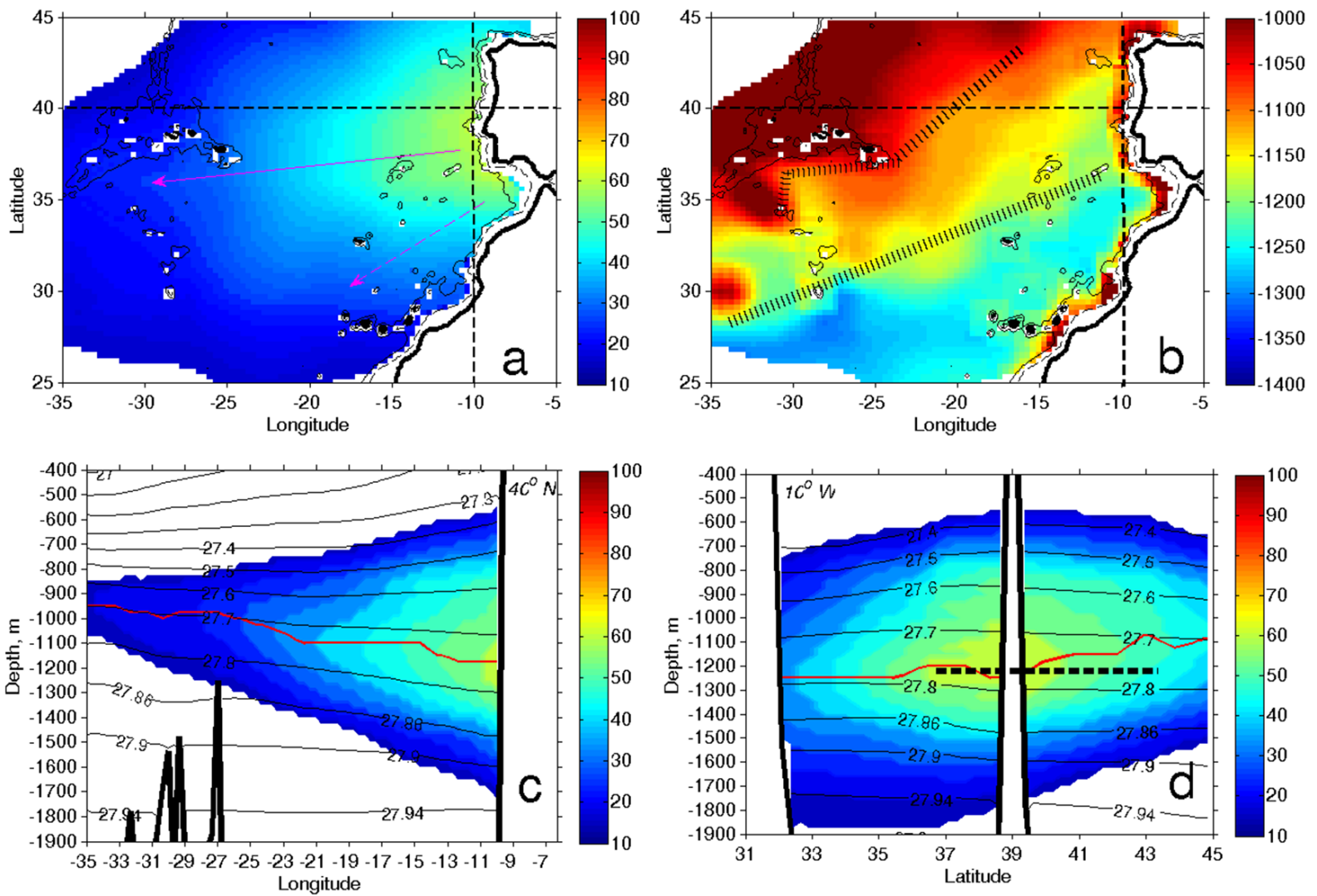

Figure 6. MW: (a) Maximum percentage in the water column, magenta lines mark suggested pathways of MW; solid line - main MW core, dashed line - lower MW core. (b) Depth (m) at which the maximum percentage in the water column is reached; the black dotted lines mark the maximum core-depth gradients. Isobaths of 500 and $2000 \mathrm{~m}$ are marked in dashed and solid black lines, respectively. Zonal and meridional sections, presented in panels (c) and (d), are marked with dashed black lines. (c) zonal section of $\mathrm{MW}$ content (\%) along $40^{\circ} \mathrm{N}$; (d) meridional section of MW content (\%) along $10^{\circ} \mathrm{W}$, (the topographic rise at $39^{\circ} \mathrm{N}$ is Estremadura Promontory). Solid black lines are neutral density surfaces. In panel (d) the black thick dashed line marks the limits of the meridional extension of the continental slope of the Iberian Peninsula to the east of the section. Red line marks the depth of the maximum content of the source water type in the water column.

$27.75 \mathrm{~kg} \mathrm{~m}^{-3}$ (around $900-1000 \mathrm{~m}$ ) and it becomes the dominating source water type (over $50 \%$ ) above 27.50 $27.65 \mathrm{~kg} \mathrm{~m}^{-3}$ (over $800-900 \mathrm{~m}$ ). LSW/NADW ${ }_{\mathrm{u}} 25 \%$ content is observed below $27.70-27.85 \mathrm{~kg} \mathrm{~m}^{-3}$ and $50 \%-$ below $27.80-27.88 \mathrm{~kg} \mathrm{~m}^{-3}$.

Over most of the region MW mixes with NACW above the neutral density surface $27.70-27.75 \mathrm{~kg} \mathrm{~m}^{-3}$ (around 1100$1200 \mathrm{~m}$ depth) and with NADW/LSW below the isopycnals. SAIW is "incorporated" into MW centre, between 27.65 and $27.80 \mathrm{~kg} \mathrm{~m}^{-3}$, which suggest that both water types strongly mixes with each other. It is this mixture which reaches as far south as $32-36^{\circ} \mathrm{N}$. Oppositely, MW boundary with mAAIW in the south is sharp.

Comparison of the OMP results with some previous studies is presented in Appendix 2.

\subsection{Advective transport of source water types}

Figure 12a presents the mean currents, derived from subsurface drifters, at $27.75 \mathrm{~kg} \mathrm{~m}^{-3}$ isopycnic surface (on average around $1100 \mathrm{~m}$ depth), where the contents of SAIW, mAAIW and MW are close to maximum (Figs. 5b, 6b and 8b). The most intensive are the bottom trapped flows: the southwards flow along the eastern slope of the MAR (see also Bower et al., 2002a) and the northwards flow along the Iberian margin (the Mediterranean undercurrent). Deep traces of the eastwards-directed North Atlantic Current at $45^{\circ} \mathrm{N}$ and the Azores Current at $35^{\circ} \mathrm{N}$ are also visible. A continuous northwards bottom trapped transport along the northwestern slope of Africa is not detected. This may be attributed to an insufficient number of observations. However, north of the Canary Islands the flow is also known to be rather weak and intermittent, which may contribute to the cause (Machín and Pelegrí, 2009). A section of the bottom trapped flow along the easternmost part of the Azores plateau together with a section of the Azores Current form a part of a large cyclonic gyre at $15-25^{\circ} \mathrm{W}$ and $34-39^{\circ} \mathrm{N}$. Other features are a weak westwards flow along $45^{\circ} \mathrm{N}$, off the northwestern corner of the Iberian Peninsula (first detected in Bower et al., 2002a), ra- 

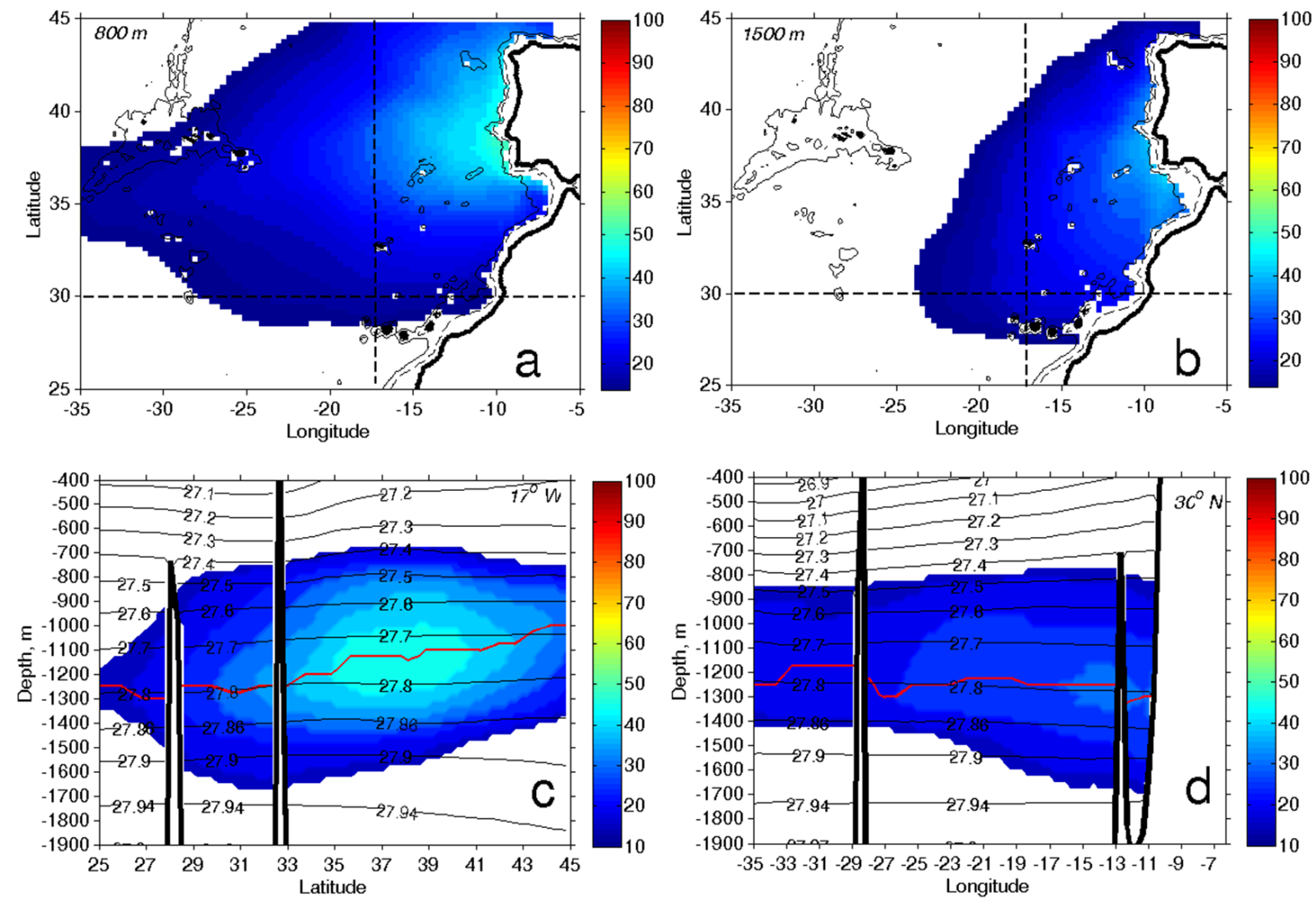

Figure 7. MW content (\%) at (a) 800 and at (b) $1500 \mathrm{~m}$ depth. Isobaths of 500 and $2000 \mathrm{~m}$ are marked in dashed and solid black lines, respectively. Zonal and meridional sections, presented in panels (c) and (d), are marked with dashed black lines. (c) meridional section of MW content (\%) along $17^{\circ} \mathrm{W}$; (d) zonal section of MW content (\%) along $29^{\circ} \mathrm{N}$. Solid black lines are neutral density surfaces. Red line marks the depth of the maximum content of the source water type in the water column.

dial spreading of water from the southwestern corner of the Iberian Peninsula (between 34 and $39^{\circ} \mathrm{N}$ ), and a continuous westwards flow southwest of the Canary Islands (between 25 and $27^{\circ} \mathrm{N}$ ). Many of the features above can also be traced along the $27.88 \mathrm{~kg} \mathrm{~m}^{-3}$ isopycnic surface (on average around $1500 \mathrm{~m}$ depth, Fig. 12c). In Fig. 12b and d the lines trace the maximum percentages of MW and of mAAIW along meridional and zonal sections, respectively, for selected depth levels. While not giving details of the advection pattern at depth, the lines show a general direction the advective-diffusive transport of the water masses (see also Tomczak and Godfrey, 2003). This is based on the following assumptions: the general direction of MW spreading is westwards and that of mAAIW is northwards; the maximum efficiency of dilution of a water mass, which is mixing with other water masses, occurs at the edges of the propagating water body. To add robustness to the computations, the lines connect the points, each of which represents the mean of the positions along a meridional or a zonal section, weighted with the respective percentages. For the computations, only the parts of the sections, where the water mass percentage exceeds $m-5 \%$ are used (where $m$ is the section maximum percentage). The lines obtained generally follow the principal mid-depth advection patterns (Fig. 12a, c). This supports the assumptions behind the computations.

Overlaying currents onto the distribution of the SAIW (Fig. 12a) suggests that advection along the eastern flank of the MAR and across the cyclonic gyre at $15-25^{\circ} \mathrm{W}$ and $34-39^{\circ} \mathrm{N}$ should play an important role in the southwards penetration of SAIW (as well as of mAAIW below). Further southwards penetration of SAIW is restricted by the Azores Current. mAAIW principally enters into the study region from the south along the African continental margin (Machín and Pelegrí, 2009). The flow is not seen in Fig. 12a due to lack of float data in the area, but can be traced from the variation of the mAAIW concentration, derived with the OMP analysis (Fig. 12b). Most of mAAIW re-circulates in the cyclonic gyre south of the Canaries and is further advected west by a zonal flow (Fig. 12a). The northernmost penetration of mAAIW west of the Canaries does not appear to be governed by a direct northwards advection (as it appears to do in Fig. 12b), but mAAIW may be transported north by an anticyclonic circulation pattern west of the Canary Islands, centred around $20-21^{\circ} \mathrm{W}$ and $28-29^{\circ} \mathrm{N}$ (Fig. 12a). A sim- 

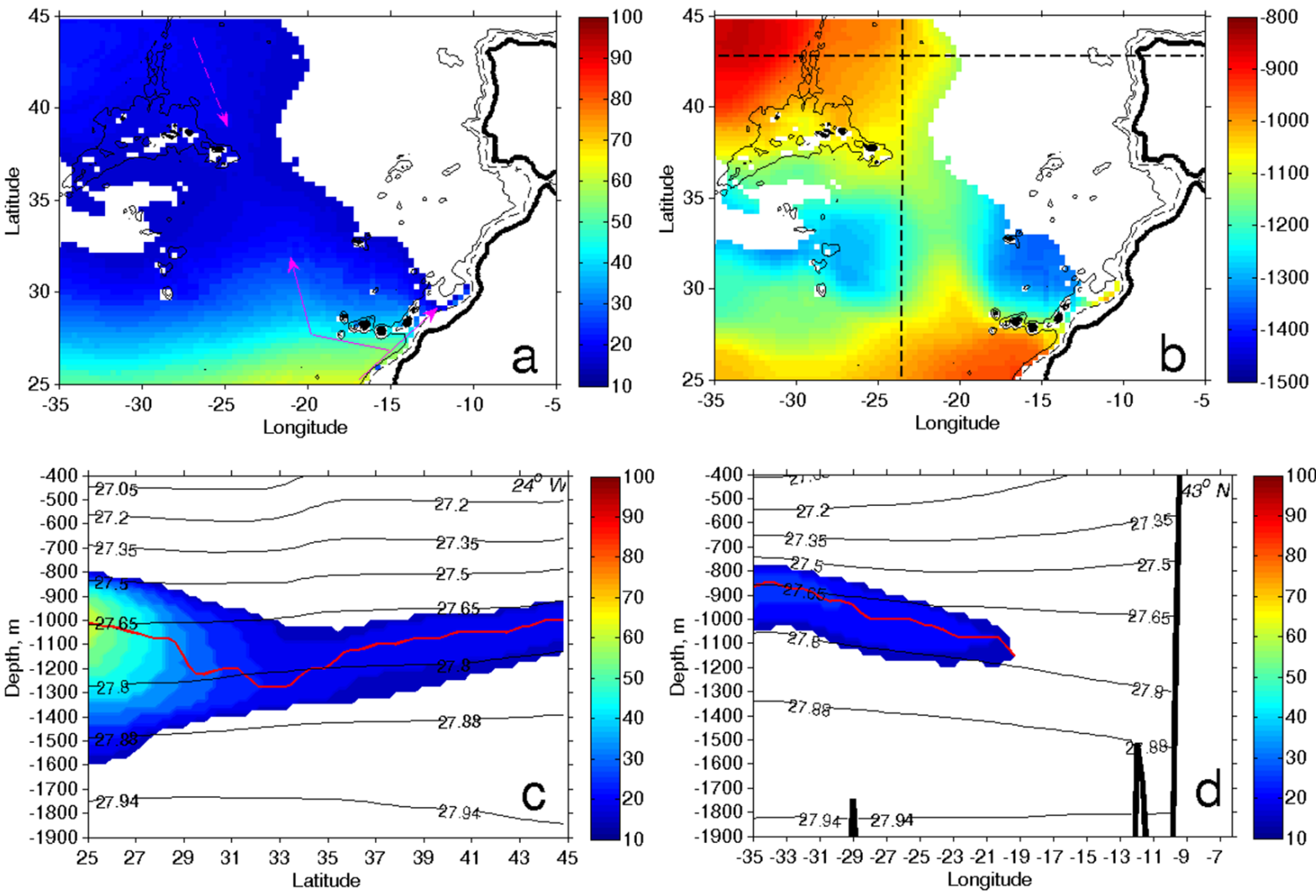

Figure 8. mAAIW: (a) maximum percentage in the water column, magenta lines mark suggested pathways of mAAIW (solid line), and modified mAAIW (dashed line); (b) depth (m) at which the maximum percentage in the water column is reached. Isobaths of 500 and $2000 \mathrm{~m}$ are marked in dashed and solid black lines, respectively. Zonal and meridional sections, presented in panels (c) and (d), are marked with dashed black lines. (c) meridional section of the mAAIW content $(\%)$ along $24^{\circ} \mathrm{W}$; (d) zonal section of the mAAIW content (\%) along $43^{\circ} \mathrm{N}$. Red line marks the depth of the maximum content of the source water type in the water column.

ilar pattern has been traced in the inverse model study by Carracedo et al. (2014).

Many features of MW spreading can be related to advection (Fig. 12a, c). In particular, MW content over $50 \%$ (east of $16^{\circ} \mathrm{W}$ ) corresponds to the area of radial water spreading from the southwestern corner of the Iberian Peninsula (Fig. 12a). A weaker westward flow north of $39^{\circ} \mathrm{N}$ and the cyclonic gyre between $15-25^{\circ} \mathrm{W}$ and $34-39^{\circ} \mathrm{N}$ apparently add to a further westward spreading of MW, whereas the eastward Azores Current form a certain barrier for the southward spreading of MW (Fig. 12a). At about $1500 \mathrm{~m}$ depth, the radial MW spreading from the Gulf of Cádiz is limited at the northwest by a southward flow, which transports water from north (Fig. 12c).

The paths, tracing MW maximum percentage, leave the Iberian margin between Cape St. Vincent and Estremadura Promontory at nearly all depth levels (Fig. 12d). The only exception is the MW path at $1800 \mathrm{~m}$, which begins in the central Gulf of Cádiz. The deeper the level, the farther south is the path.
To better understand the role of advection-diffusion fluxes in spreading of the mid-depth source water types, currents are interpolated to local depths of the cores of the source water types (Fig. 13). The current vectors $(\boldsymbol{V})$ are further decomposed into along-isoline $(v)$ and cross-isoline $\left(v_{\perp}\right)$ components, relative to the isolines of the source water type concentration (Figs. 5a-b, 6a-b and 8a-b). Furthermore, we assume that climatic distributions of the source water type concentrations are determined by a local balance between advection and turbulent diffusion: in particular, the turbulent flux of the source water type concentration should balance the cross-isoline component of the flow (Zika et al., 2010):

$v_{\perp} \frac{\partial C}{\partial n}=\left[K_{1} \frac{\partial^{2} C}{\partial n^{2}}+K_{z} \frac{\partial^{2} C}{\partial z^{2}}\right]=F_{\text {diff }}$

Here $C$ is the source water type concentration, $n$ is a normal to the isoline of $C, K_{1}$ and $K_{z}$ are the coefficients of horizontal and vertical diffusivity, respectively.

In Fig. 13 the magenta vectors show the areas where advection spreads the source water type away from the source, i.e. where $v_{\perp}$ is directed along the local gradient of the source 

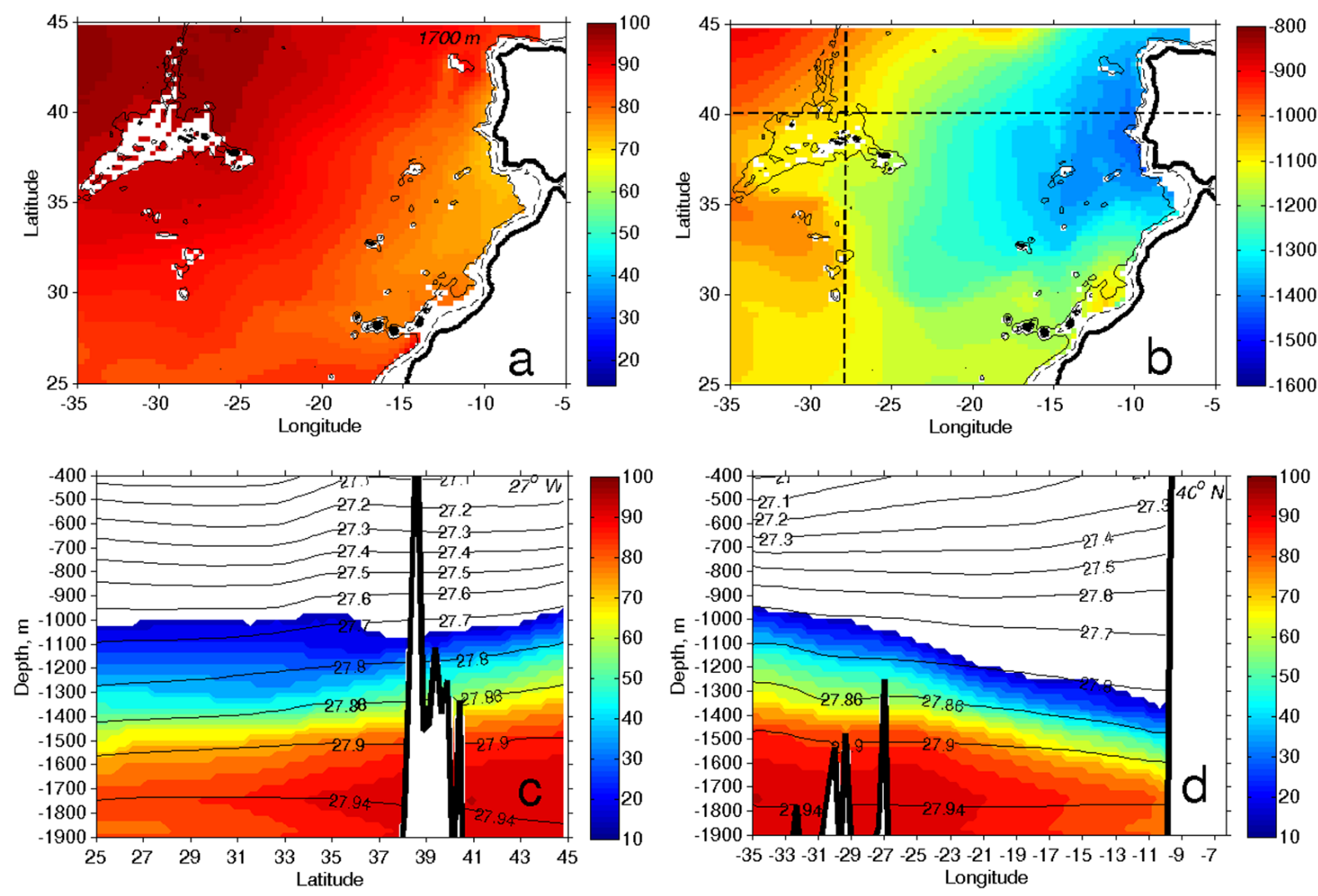

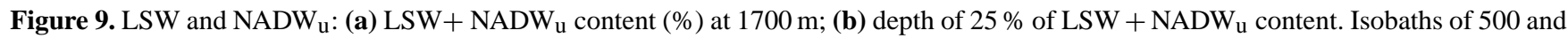
$2000 \mathrm{~m}$ are marked in dashed and solid black lines, respectively. Zonal and meridional sections, presented in panels (c) and (d), are marked with dashed black lines. (c) meridional section of $\mathrm{LSW}+\mathrm{NADW}_{\mathrm{u}}$ content (\%) along $27^{\circ} \mathrm{W}$; (d) zonal section of $\mathrm{LSW}_{+} \mathrm{NADW}(\%)$ along $40^{\circ} \mathrm{N}$.

water type concentration and $v_{\perp}>v_{\text {err. }}$. The error in determination of the current velocity $\left(v_{\text {err }}\right)$ is defined in Appendix 1. The ratio of $v_{\perp}$ to the overall current velocity $V=\sqrt{v_{\perp}^{2}+v^{2}}$ gives an idea of the relative importance of diffusion to advection in the spreading of a water mass.

The most intensive westwards advective transport of the main MW core is along $39^{\circ} \mathrm{N}$, which corresponds to the principal direction of spreading of MW main core. Predominantly southwestward currents from the Gulf of Cádiz explain the southward path of MW lower core (Fig. 13a). Both flows are directed almost perpendicular to the isolines of MW concentration, suggesting that MW advection is balanced with an intensive turbulent mixing with the surrounding water. The result is a rapid drop of MW concentration in the direction of the mean flow (Fig. 13a).

Using the gradients of the source water type concentrations, the overall turbulent diffusion fluxes $\left(F_{\text {diff }}\right)$ can be evaluated (Fig. 13b). MW diffusion is expected to be especially strong (blue arrows in Fig. 13) in a cyclonic recirculation southwest of the Galicia Bank, at the northeastern tip of the Azores plateau and in the lower Azores Current at $34-35^{\circ} \mathrm{N}$ and $26-17^{\circ} \mathrm{W}$. The latter two occasions are the regions of comparatively intensive jet flows, where stronger turbulent fluxes are anticipated. Those areas are also known as the areas of meddy decay: at the seamounts of the Azores plateau (Richardson et al., 2000; Bashmachnikov et al., 2009), as well as in the lateral shear of the Azores Current (Maximenko and Orlov, 1991; Bashmachnikov et al., 2015b). Mediterranean water eddies (meddies) conserve the original MW properties even after having travelled far away from the Iberian margin (Bashmachnikov et al., 2015b). Therefore, in the location of their rapid decay a higher MW contents is injected into the surrounding water. Along the Azores current, meddies, lateral mixing and $\mathrm{MW}$ re-circulations, appear to somewhat compensate for the effect of the eastward advection of NACW/LSW water along the Azores Current and to reduce the gradients of MW contents across the current. mAAIW (Fig. 13c) is mostly advected along isolines of its own concentration. SAIW (Fig. 13d), as it penetrates south along the MAR, strongly mixes with the surrounding water. Since east of the Azores plateau SAIW penetrates into the MW core (Figs. 10-11), we may speculate that further south the water types spread together as a mixture.

Figure $12 \mathrm{~d}$ gives evidence that MW separates from the Iberian margin mostly between Cape St. Vincent and Es- 

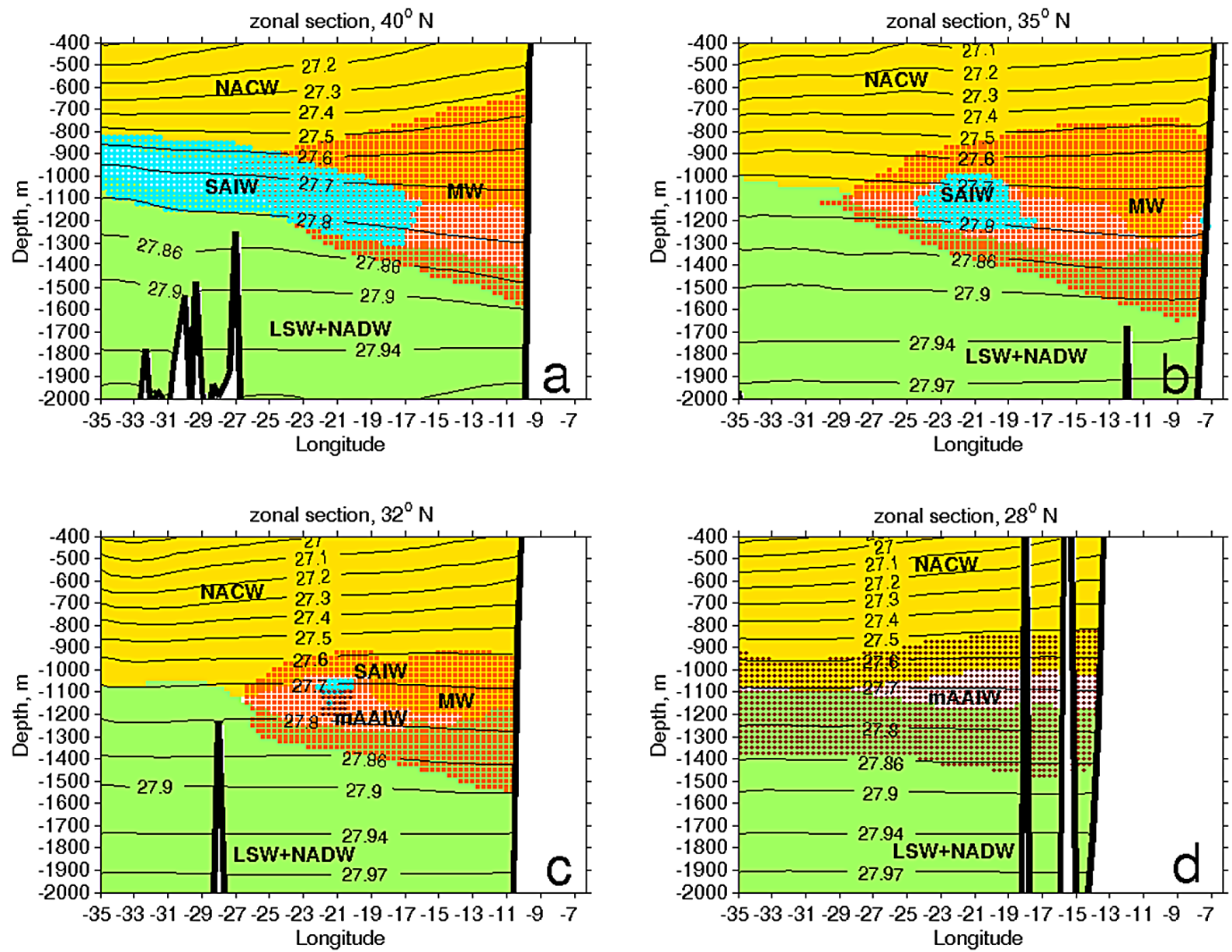

Figure 10. Distribution of water masses, the contribution of which exceeds $25 \%$, along zonal sections: (a) $40^{\circ} \mathrm{N}$, (b) $35^{\circ} \mathrm{N}$, (c) $32^{\circ} \mathrm{N}$, (d) $28^{\circ} \mathrm{N}$. Yellow is NACW, green - LSW and NADW, orange - MW, cyan - SAIW, brown - mAAIW. Note, that there is an overlap of different water masses at some areas, since in a point more than one water mass may have contribution over $25 \%$.

tremadura Promontory (see also Daniault et al., 1994; Iorga and Lozier, 1999a). This part of the Iberian continental slope is also known to be the region of the most intensive meddy generation/detachment from the slope (Daniault et al., 1994; Bower et al., 2002b, Bashmachnikov et al., 2015b). The in the following discussion we suggest that this is due to a local increase of the Joint Effect of Baroclinicity and Bottom Relief (JEBAR) and of the planetary $\beta$ effect as compared to the topographic $\beta$ effect.

Integrated over an ocean layer, geostrophic relations in the baroclinic ocean are combined with the continuity equation to obtain a well-known expression (Pedlosky, 1998):

$\frac{\beta v}{f}-\frac{V \cdot \nabla H}{H}=\frac{1}{f H^{2}} J(\Phi, H)$.

Here $\beta$ is the variation of the Coriolis parameter with latitude, $H$ is the water depth, $\nabla H$ is the water depth gradient, $\boldsymbol{V}$ is the layer-mean current velocity and $v=|\boldsymbol{V}| \cos \gamma$ is its northern component, $\gamma$ is the angle between the geographic north and the direction of the flow, $J(\Phi, H)=$ $\frac{\partial \Phi}{\partial x} \frac{\partial H}{\partial y}-\frac{\partial \Phi}{\partial y} \frac{\partial H}{\partial x}, \Phi=\frac{1}{\rho_{0}} \int_{-H}^{-H_{1}}\left(\int_{-H}^{-z} g \rho \mathrm{d} z^{\prime}\right) \mathrm{d} z$, and $H_{1}$ is the upper limit of the layer of interest. In Eq. (3) the first term describes the planetary $\beta$ effect, the second term - the topographic $\beta$ effect and the third term - the JEBAR.

In Eq. (3) we neglect friction, since the Ekman number $E=\frac{K}{\bar{f} L^{2}}$ is much less than 1 . In fact, taking the coefficient scale of the MUC $L \sim 50 \mathrm{~km}$ and the coefficient of horizontal diffusion $K \sim 0.002 L^{4 / 3} \sim 3700 \mathrm{~m}^{2} \mathrm{~s}^{-1}$, we get $E \sim 10^{-2}$. Analysing the intensity of bottom friction, Price et al. (1993) showed that even within the first $100 \mathrm{~km}$ from the Gibraltar Strait, where $V$ is over $50 \mathrm{~cm} \mathrm{~s}^{-1}$, the corresponding $E \sim 0.2$. It reduces further away from the Strait with the decrease of the MUC velocity.

In the absence of external sources or sinks of relative vorticity, Eq. (3) imposes strict limitations on the direction of a geostrophic flow. When a current does not reach the bottom, only the planetary $\beta$ effect is different from zero and a geostrophic flow goes zonal $(v=0)$. When the flow reaches 

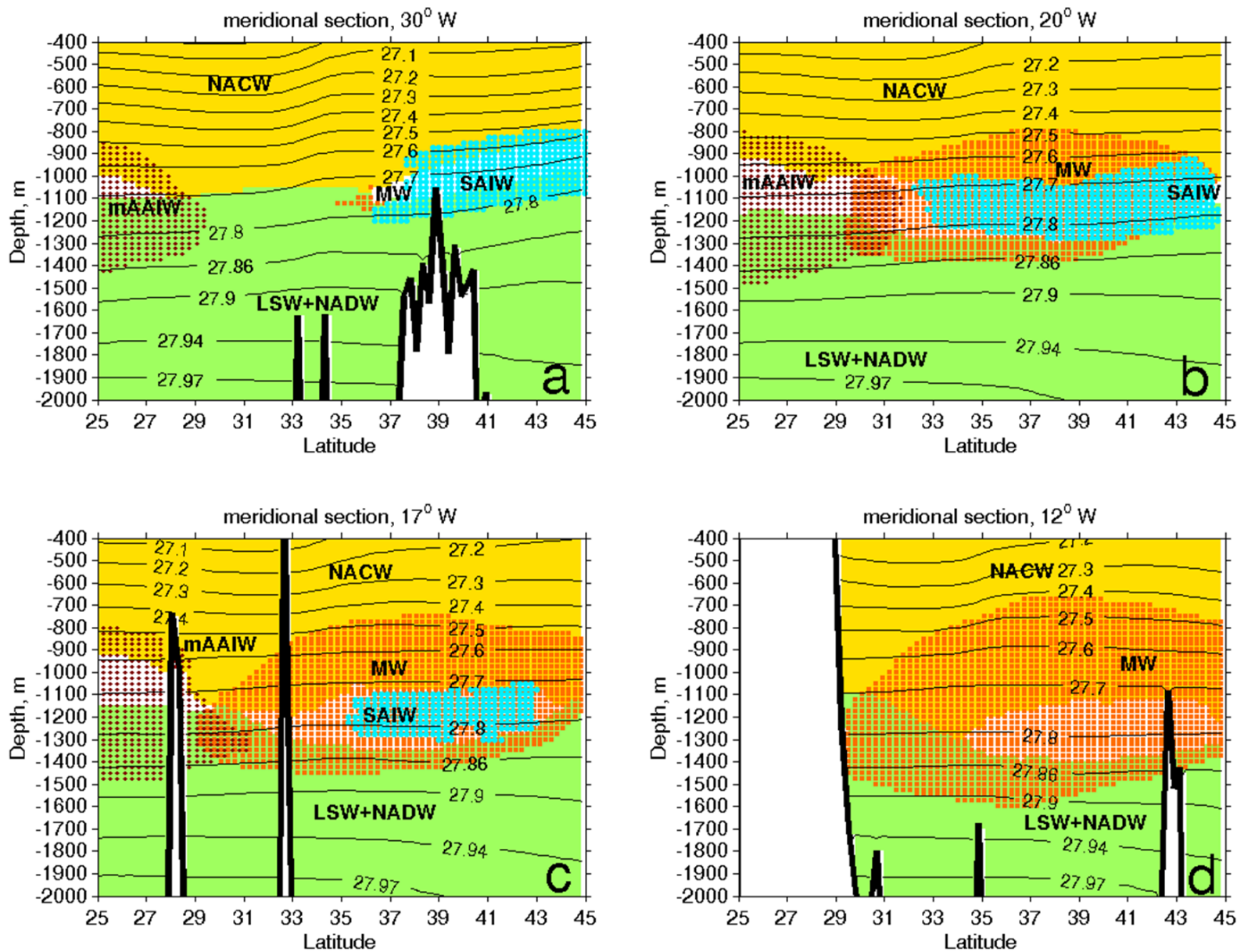

Figure 11. Distribution of water masses, the contribution of which exceeds $25 \%$, along meridional sections (a) $30^{\circ} \mathrm{W}$, (b) $20^{\circ} \mathrm{W}$, (c) $17^{\circ} \mathrm{W}$, (d) $12^{\circ} \mathrm{W}$. Yellow is NACW, green - LSW and NADW, orange - MW, cyan - SAIW, brown - mAAIW. Note the overlap of different water masses in some areas, since at any given point more than one water mass may have contribution over $25 \%$.

the bottom and the bottom slope is steep enough, the topographic $\beta$ effect and JEBAR becomes dominant. The topographic $\beta$ effect forces a geostrophic flow to follow the isobaths $(\boldsymbol{V} \cdot \nabla H=0)$, while JEBAR may tend to deflect it from the along-isobath direction.

As the MUC progresses north, conservation of potential vorticity suggests formation of a negative relative vorticity anomaly. This might result in an instability or meandering of the flow. The meanders detach the flow from the slope, where the topographic effects dominate its dynamics. At that point, conservation of potential vorticity of the flow may already be dominated by variation of the Coriolis parameter, which requires a zonal direction of the flow.

Since the depth limits of the MUC are 500/600 m and 1400/1500 m (Ambar and Howe, 1979; Ambar et al., 2008; Baringer and Price, 1997; Bashmachnikov et al., 2015a), the function $\Phi$ of JEBAR can be integrated over the MW water layer, from 600 to $1500 \mathrm{~m}$ (or all the way to the bottom). The computed JEBAR field is quite patchy. Over a steep slope $\nabla \Phi$ is almost parallel to $\nabla H$ and both terms, $\frac{\partial \Phi}{\partial x} \frac{\partial H}{\partial y}$ and $\frac{\partial \Phi}{\partial y} \frac{\partial H}{\partial x}$, have the same sign. The difference of the two comparatively large values is sensitive to even small errors in determination of $\nabla \Phi$ or $\nabla H$. In further estimates of JEBAR, topographic and planetary $\beta$ effects, we use the sliding median values taken within the window limited by the $500 \mathrm{~m}$ and $2000 \mathrm{~m}$ isobaths (the lower limit of the vertical integration is always above $1500 \mathrm{~m}$ ) and $\pm 25 \mathrm{~km}$ in the alongisobath direction (henceforth referred to as the slope). JEBAR is also estimated along the deep part of the slope - with the window limited by the projections of 1500 and $2500 \mathrm{~m}$ isobaths on the $1500 \mathrm{~m}$ level and $\pm 25 \mathrm{~km}$ in the along-isobath direction (henceforth referred to as the outer slope).

Computations with the MEDTRANS climatology suggest that along the slope of the Iberian Peninsula, the median values of the topographic $\beta$ effect exceed the planetary $\beta$ effect and JEBAR. At the same time, there are places where JEBAR exceeds the topographic $\beta$ effect: south of Cape St.Vincent, around Estremadura Promontory, near Porto-Aveiro canyons, 

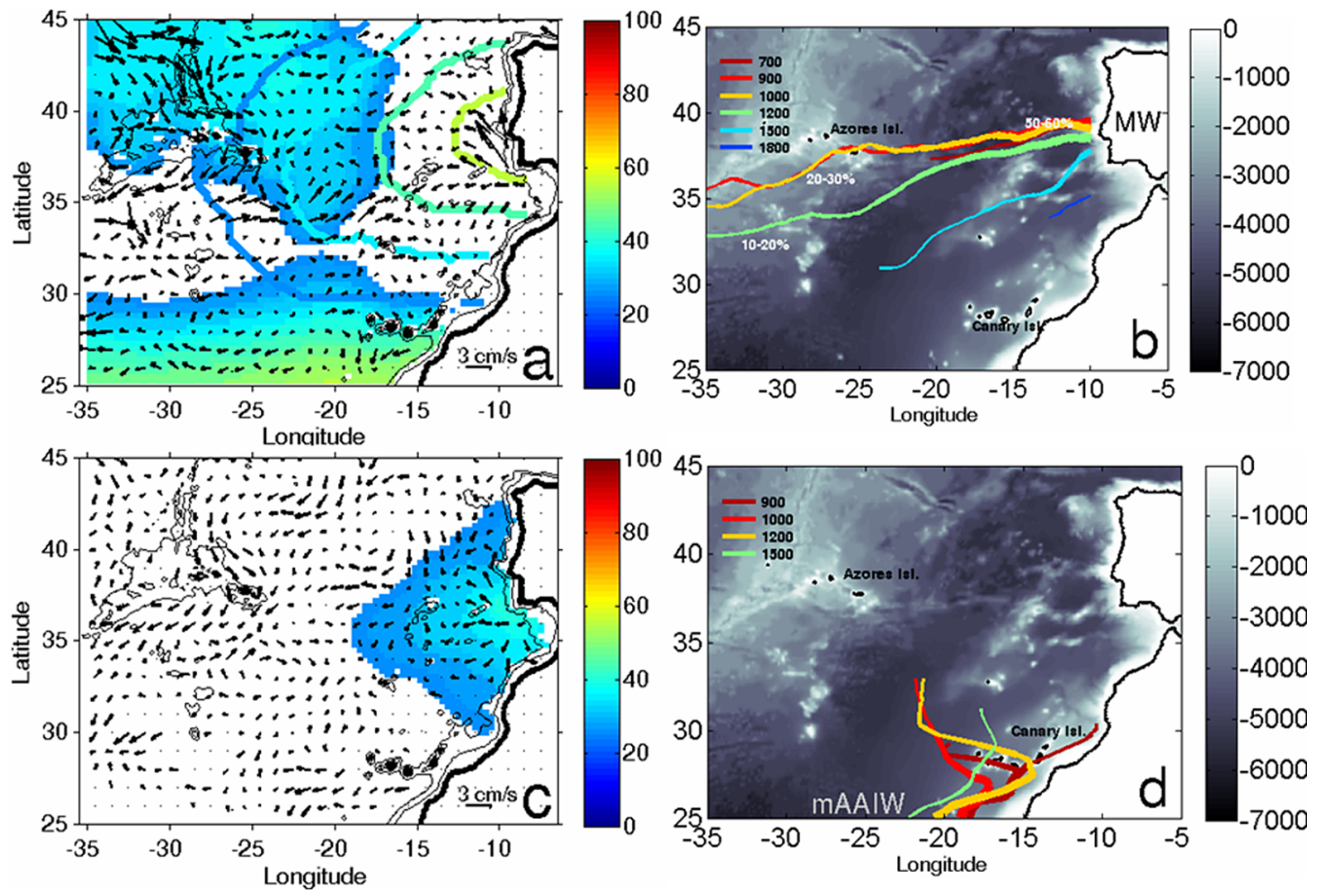

Figure 12. (a) Source water type contents (\%) at $27.75 \mathrm{~kg} \mathrm{~m}^{-3}$ (from 950 to $1200 \mathrm{~m}$ depth): SAIW (northwest, colour), mAAIW (south, colour) and MW (west, contours). Only source water type concentrations over $25 \%$ are presented. Current vectors at $1100 \mathrm{~m}$ depth are overlaid. (b) Paths of mAAIW at different depth levels based on variation of the source water type contents. (c) MW contents (\%,colour) at $27.88 \mathrm{~kg} \mathrm{~m}^{-3}$ (from 1350 to $1550 \mathrm{~m}$ depth). Only the source water type concentrations over $25 \%$ are presented. Current vectors at $1500 \mathrm{~m}$ depth are overlaid. (d) Paths of MW at different depth levels based on variation of the source water type contents. In panels (b) and (d): dark red is $600 \mathrm{~m}$, red $-900 \mathrm{~m}$, yellow $-1000 \mathrm{~m}$, green $-1200 \mathrm{~m}$, light blue $-1500 \mathrm{~m}$, thin dark blue line $-1800 \mathrm{~m}$. The line thickness in (d) demonstrates MW contents, which varies from 30-60\% in the east to $10-20 \%$ in the west of the region.

west and north of Cape Finisterre and north of Cape Ortegal (Fig. 14). In particular, JEBAR is strong at Estremadura Promontory. This area has been shown to be the preferred place for MW to leave the Iberian margin (Figs. 12a, b, 13a).

In about $40 \%$ of the points along the Iberian margin, JEBAR is at least 2 times less than the planetary $\beta$ effect, and may be neglected. We can therefore estimate the relative intensity of the topographic to planetary $\beta$ effects as

$R_{\beta}=\frac{|\nabla H| / H}{\beta / f \cos \gamma}$.

The greater the value of $R_{\beta}$, the stronger is the bottom trapping of the MUC, and the more difficult it is for the MUC to detach from the Iberian margin under the external forcing of the same intensity. Figure 14 presents two areas of minimum $R_{\beta}$ : between Cape St. Vincent and Estremadura Promontory and northwest of Cape Ortegal. Those areas are the most vulnerable to destabilisation of the MUC by external forcing, which should result in an overall stronger local seawards flux of MW.

\section{Discussion and conclusions}

This study presents the systematic quantitative estimate of climatological distribution of the mid-depth source water type contents (the source water type volume in a unit volume of water) in the NE Atlantic. This is a continuation of similar studies for the NW Atlantic (Hinrichsen and Tomczak, 1993), NACW content in the North Atlantic (Poole and Tomczak, 1999), qualitative analysis of water mass distribution in the region (van Aken, 2000a, b, 2001), as well as analyses of particular synoptic sections (Pérez et al., 1998, 2001; Cabeçadas et al., 2002; Alvaréz et al., 2004; Barbero et al., 2010; Louarn and Morin, 2011; Pastor et al., 2012).

The content of each of the source water types at any given point depends on the choice of the source water types used in the analysis, as well as on the choice of their characteristics, which may also differ from one work to another. The spatial variation of the source water type content is much less sensible to this choice and presents a more objective result. From this point of view, the outlined spatial distribution 

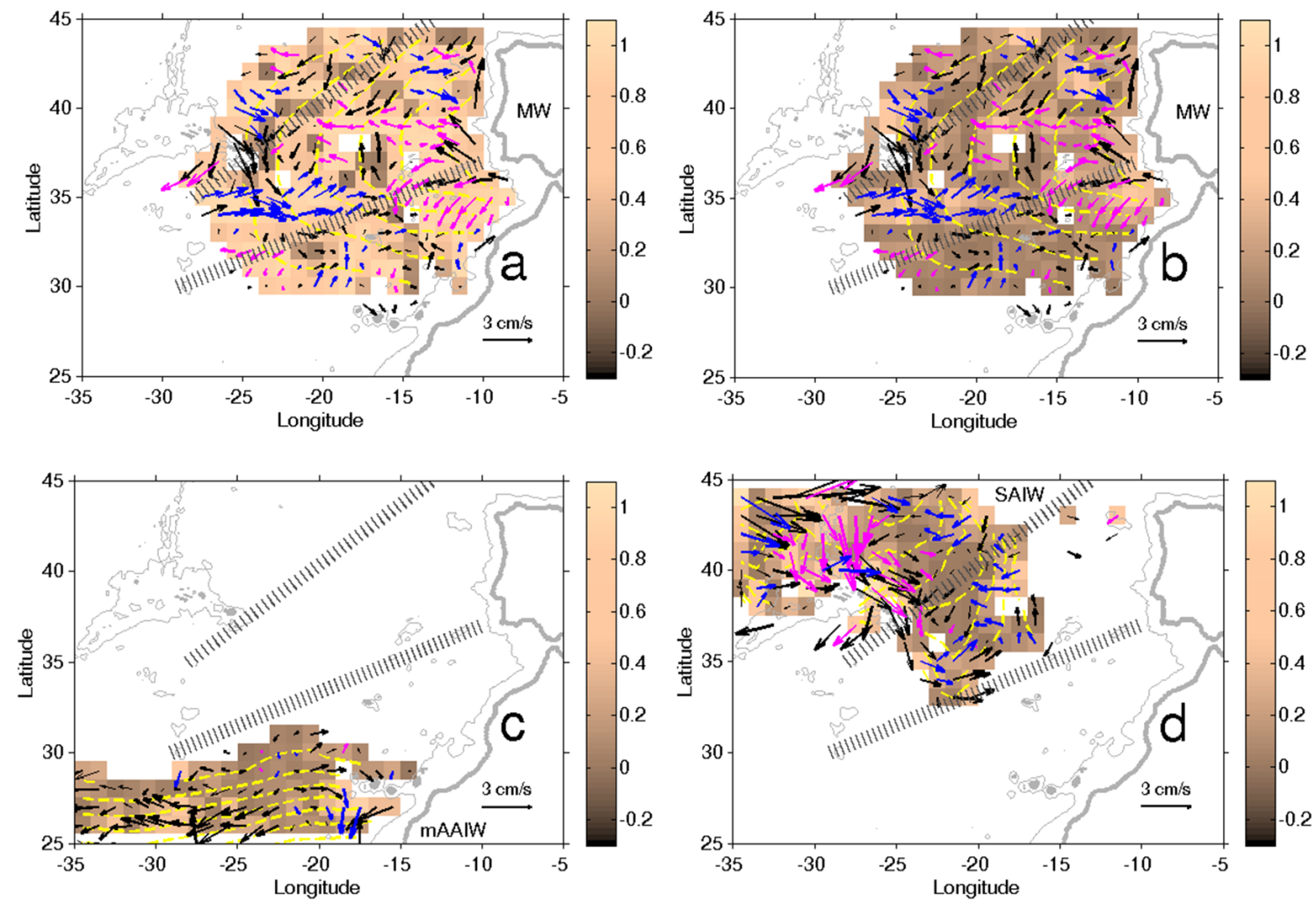

Figure 13. The role of advective and diffusive fluxes in the spreading of water types. Colour in panel (a) is $|v / V|$ over MW; the lighter the shade, the more exact is the advection balanced by the diffusive dispersion of the source water type. Panels (b), (c) and (d) represent the overall intensity of the diffusive fluxes $\left(F_{\text {diff }}\right)$ for MW, mAAIW and SAIW, respectively. Currents at the core depth of the respective source water type are marked with thin black arrows (the error in definition of the current velocity ranges from $50 \%$ to $100 \%$ ) and thick black/magenta/blue arrows (the error in definition of the current velocity is below 50\%). Yellow contours represent isolines of concentration of the respective source water type; see Figs. 5a, 6a and $8 \mathrm{a}$ for the absolute values. Black arrows additionally mark the currents that advect concentrations predominantly along the isolines of the source water type concentration, magenta - away from the source water type source (from higher to lower source water type concentration), blue - towards the source (from lower to higher source water type concentration). The boundaries of the three MW cores are marked as dotted grey lines. Solid grey lines present the $2000 \mathrm{~m}$ isobath and the coastline.

of the depths of the cores of the source water types can be considered as a robust result of this study (Figs. 5-8). The variations of the core depths are found to match well with the corresponding variations of the depths of neutral density surfaces, giving an additional argument for the robustness of the analysis. Another argument is that directions of the main source water type pathways at different depth levels, derived from examination of the results of the OMP analysis, correspond well with the advection patterns, derived from independent drifter data sets.

The new features and additional details of the previously known distributions of the mid-depth source water types described in the Introduction are given below.

\subsection{MW}

In the Atlantic, away from the Iberian margin, MW spreading has been previously described as being separated into two cores (Harvey and Arhan, 1988): one maximum at 800-
$1000 \mathrm{~m}$ (between 30 and $40^{\circ} \mathrm{N}$ ) and another maximum at $1500-1900 \mathrm{~m}$ (between 28 and $30^{\circ} \mathrm{N}$ ). Our results suggest that three MW cores can be identified, separated by continuous transition lines: across each of the transition lines MW core density and depth change abruptly (Figs. 6b, c and 7c).

The upper MW core is found between the MAR and the transition line between $28^{\circ} \mathrm{W}, 35^{\circ} \mathrm{N}$ and $14^{\circ} \mathrm{W}, 44^{\circ} \mathrm{N}$ (Fig. 6b). This transition line details the northwestern boundary between the main MW core and SAIW/LSW, presented by van Aken (2000b). In fact, the maximum MW contents in the upper core is rather low -10 to $25 \%$ (Figs. 6a and 12a). The highest percentage of MW is found within the neutral density range of $27.65-27.70 \mathrm{~kg} \mathrm{~m}^{-3}(900-1000 \mathrm{~m})$. This corresponds to the neutral density of the maximum MW concentration at the northwestern tip of the Iberian Peninsula (Fig. 6d) and further north (Iorga and Lozier, 1999a). The pattern of mid-depth currents in the area confirms a possible westward, and farther away a southward, MW advection 


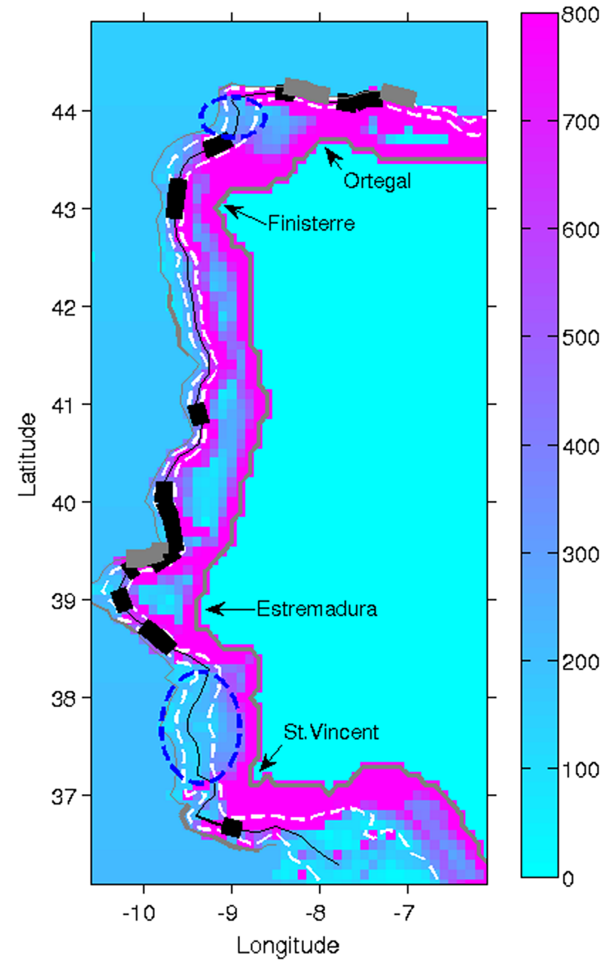

Figure 14. Topographic $\beta$ effect, planetary $\beta$ effect and JEBAR along the Iberian margin. Spatial distribution of $R_{\beta}$. The thickness of $1000 \mathrm{~m}$ isobath (solid black line) and $2000 \mathrm{~m}$ isobath (solid grey line) shows the effect of JEBAR relative to the topographic $\beta$ effect. Isobaths of $500 \mathrm{~m}$ and $1500 \mathrm{~m}$ (white dashed lines) are marked.

from the northwestern corner of the Iberian Peninsula to the MAR north of the Azores (Figs. 12a and 13a, b).

The main MW core extends from the above-mentioned transition line to the second transition line between $35^{\circ} \mathrm{W}$, $28^{\circ} \mathrm{N}$ and $10^{\circ} \mathrm{W}, 37^{\circ} \mathrm{N}$ (Fig. 6b). The maximum MW content in the core reaches $50-60 \%$ (Fig. 6a). In the MW core, the majority of the water has a neutral density around $27.75 \mathrm{~kg} \mathrm{~m}^{-3}$ and is observed at the depths of $1000-1100 \mathrm{~m}$ (Figs. 6 and 7). The neutral density of the main MW core in the Atlantic is the same as that of the MUC along the western Iberian slope (Fig. 6d). However, MW primarily separates from the Iberian margin from the Estremadura Promontory and the slope region around (Fig. 12d), where JEBAR is found to be strong enough to detach the MUC from the continental margin. Some MW flow can also detach from the region between Cape St.Vincent and Estremadura Promontory, where a local decrease of the topographic $\beta$ effect is observed (Fig. 14). The main MW core presents the majority of MW water in the Atlantic. Figure $13(\mathrm{a}, \mathrm{b})$ suggests that a westwards deep flow between 38 and $40^{\circ} \mathrm{N}$ plays an important role in its westwards transport. The possible role of advection in the spreading of the main MW core north of $36^{\circ} \mathrm{N}$ has been previously suggested by Sparrow et al. (2002), although mid-depths currents in the area are weak, i.e. on the order of few $\mathrm{cm} \mathrm{s}^{-1}$, and may be intermittent (Barbero et al., 2010). Another possible mechanism is MW spreading with meddies, the relative role of which is still unclear (Richardson et al., 2000; Bashmachnikov et al., 2015b).

The lower MW core, southeast of the second transition (Fig. 6b), extends from the Gulf of Cádiz southwestwards. The maximum MW content in the core reaches $50 \%$ in the Iberian basin, but drops below $40 \%$ already south of the Azores Current (Fig. 6a). MW maximum percentage in the core has neutral density around $27.80 \mathrm{~kg} \mathrm{~m}^{-3}$ and is observed at $1250-1350 \mathrm{~m}$. The density exceeds that of the MUC even at the southern slope of the Iberian Peninsula $\left(27.75-27.77 \mathrm{~kg} \mathrm{~m}^{-3}\right)$. The similar density in the vicinity of the Iberian Peninsula is observed only in the Gulf of Cádiz $\left(27.79-27.80 \mathrm{~kg} \mathrm{~m}^{-3}\right)$. Only here MW influences the water column down to 1800-1900 m (Fig. 6d). Trapping of MW in the cyclonic circulation of the Gulf of Cádiz (some traces of the cyclonic gyre can be seen in Fig. 12a, c), together with the anomalously low stratification of its deep waters (Iorga and Lozier, 1999a), apparently favour MW vertical diffusion/double diffusion to deeper layers. The deep MW from the Gulf of Cádiz preferably spreads southwest, parallel to the African margin, following the direction of the mean currents at those depths (Fig. 13a, b). The lower MW core spreads farther west forming the boundary with the mAAIW transition at $26-29^{\circ} \mathrm{N}$ (Figs. 6b, 7c-d). MW is known to mix with both NACW and NADW (Price et al., 1993; van Aken, 2000b; Barbosa Aguiar et al., 2014). Our results show that the vertical boundary between MW mixture with NACW and MW mixture with NADW/LSW passes between the neutral density surface $27.70-27.75 \mathrm{~kg} \mathrm{~m}^{-3}$, at around $1100-1200 \mathrm{~m}$ depth (Figs. 10-11). MW maximum contents in the MUC of around $65 \%$ stays nearly constant along the Iberian margin up to $40-41^{\circ} \mathrm{N}$, immediately north of Estremadura Promontory, gradually decreasing further north (see also Daniault et al., 1994). The relatively low percentage of MW in the area of the definition of the source water type parameters (the lower core of the MUC at $7^{\circ} \mathrm{W}$ ) is a result of an artificial dilution of MW contents in the MUC in MEDTRANS (and other climatological data sets), which do not capture sufficiently well the narrow MUC (50 km or less in this area). The MEDTRANS data set represents fairly well MW salinity in the MUC only downstream of $8-9^{\circ} \mathrm{W}$, (between Portimao Canyon and Cape St.Vincent), where the width of the MUC reaches $80 \mathrm{~km}$ and is comparable to the data set gridding radius (Bashmachnikov et al., 2015a). Meanwhile, between 7 and $9^{\circ} \mathrm{W}$, the MUC transport increases by $25 \%$ due to entrainment of NACW/NADW (Rhein and Hinrichsen, 1993). The expected MW dilution to $75 \%$ of its contents at $7^{\circ} \mathrm{W}$, is close to the estimate obtained by the OMP analysis within the $10 \%$ error.

Our results suggest that JEBAR forms the main mechanism for detachment of the MUC from the continental margin. It can be also noted that the areas of strong JEBAR effect (Fig. 14) well correspond to those of meddy generation and 
detachment (Richardson et al., 2000; Bashmachnikov et al., $2015 b$ ). Since it has been shown that, in the absence of external forcing, meddies, generated in the MUC, are propagating along the continental slope and are trapped by topography (Aiki and Yamagata, 2004), we can speculate that JEBAR may equally facilitate meddy detachment from the continental margin.

\subsection{SAIW}

The area of influence of SAIW has not been thoroughly studied in literature. Our study confirms that SAIW spreads south along both sides of the MAR up to the Azores plateau, and nearly reaches the Iberian Peninsula to the east (McCartney and Talley, 1982; Harvey and Arhan, 1988; Arhan, 1990). At the same time, our study demonstrates that southward spreading of SAIW east of the MAR is not limited to $40^{\circ} \mathrm{N}$ (McCartney and Talley, 1982; Harvey and Arhan, 1988; Arhan, 1990), but a considerable concentration of SAIW penetrates (between 20 and $25^{\circ} \mathrm{W}$ ) as far south as the Azores Current and furthermore spreads over in the cyclonic gyre at $15-25^{\circ} \mathrm{W}$ and $34-39^{\circ} \mathrm{N}$. The substantially diluted SAIW has not been reported that far south due to the difficulty in differentiation of SAIW-MW mixture from that of MW-NACW or MW-LSW/NADW, using traditional visual inspection of the $\theta-\mathrm{S}$ diagrams.

The density of SAIW core $\left(27.70-27.75 \mathrm{~kg} \mathrm{~m}^{-3}\right)$ is in the range of the densities of the upper and the main MW cores (Figs. 10-11). The mixture between MW and SAIW most probably occurs between 42 and $44^{\circ} \mathrm{N}$ and the northeastern slope of the Azores plateau.

\section{3 mAAIW}

The results of this study confirm that the overall northern limit of mAAIW is situated between 25 and $32^{\circ} \mathrm{N}$ (Tsuchiya, 1989; Tsuchiya et al., 1992; Pérez et al., 2001; Llinás et al., 2002; Alvaréz et al., 2004; Machín et al., 2006; Machín and Pelegrí, 2009; Pastor et al., 2012). South of $29^{\circ} \mathrm{N}$, the mAAIW core is positioned between the neutral density surfaces of $27.60-27.65 \mathrm{~kg} \mathrm{~m}^{-3}$, at around 900-1000 m. North of $29^{\circ} \mathrm{N}$, mAAIW contents sharply drops down (substituted by $\mathrm{MW}$ ) and its core is found already between 27.80 and $27.85 \mathrm{~kg} \mathrm{~m}^{-3}$, at $1200-1300 \mathrm{~m}$. The deepening is most drastic across the Canary Islands, which presents a natural barrier for mAAIW spreading north. mAAIW-MW transition occurs as a jump also west of the Canaries, where both source water types are transported westwards by a deep flow (Figs. 8c and 13c). mAAIW penetrates north of the Canary Islands as a narrow jet along the African coast of only 50$30 \mathrm{~km}$ wide (Machin et al., 2006; Machin and Pelegrí, 2009), but its concentration drops sharply by $25-30 \%$ at $30^{\circ} \mathrm{N}$ to less than $10 \%$ at $30.5^{\circ} \mathrm{N}$ (Figs. $8 \mathrm{~b}$ and $12 \mathrm{~d}$ ). If we slightly modify mAAIW characteristics, some small percentage of mAAIW (of order of $10 \%$ ) is detected to follow the African coast up to the Gulf of Cádiz (not shown). This has been detected by Louarn and Morin (2011). However, a detailed analysis of individual sections shows that mAAIW transport at $32^{\circ} \mathrm{N}$ is already weak and intermittent (Machin et al., 2006; Machin and Pelegrí, 2009).

Our study also suggests that mAAIW penetrates relatively far north west of the Canary Islands (Figs. 8a and 12b). Its anomalous northwards penetration can be a result of mAAIW being trapped in an anticyclonic circulation northwest of the islands (Figs. 12a-c and 13c; see also Carracedo et al., 2014). 


\section{Appendix A}

\section{A1 Obtaining gridded Eulerian velocity fields from Argo and RAFOS data sets}

In this section we describe the methodology for obtaining gridded fields of the Eulerian currents from Argo and RAFOS drifter data sets.

The first step is to detect and remove parts of the drifter trajectories within mesoscale eddies. This is done to avoid the related bias, since mesoscale eddies are known to often have velocities significantly different from those of the ambient flow, and may even travel against the flow (Morel, 1995). In particular Mediterranean water eddies (meddies) were filtered out, as the strongest mid-depth eddies in the subtropical NE Atlantic, easily detectable due to strong temperaturesalinity anomalies and high anticyclonic rotation velocities. Differences in the sampling periods (rotations in mesoscale eddies have characteristic periods of 3-10 days and can be registered in RAFOS, but not in Argo data) and the observed water properties (the majority of the RAFOS floats register only along-track temperature and pressure, while Argo floats supply vertical temperature-salinity profiles from $2000 \mathrm{~m}$ to the sea surface at the end of every sampling period) suggest an adaptation of the eddy identification algorithm for each of the data sets. A RAFOS float is defined as being trapped in an eddy, if it forms at least two complete rotations within a 20day interval. Comparison with literature shows that most of the mid-depth eddies identified in this study have been previously detected as meddies (Richardson et al., 2000; Ambar et al., 2001; Bashmachnikov et al., 2015b). Meddies are identified in Argo vertical profiles as salinity anomalies of 0.2 or more, persistent over more than 200 m layer within 500 $1500 \mathrm{~m}$ depth interval (Richardson et al., 1991). The MEDTRANS climatologic salinity is taken as the reference field. A part of an Agro trajectory is removed when a meddy is detected for at least a 20-day period. For the typical 10-day Argo sampling period this means a meddy detection in at least 3 consequent vertical profiles.

The float trajectories are further collected for the selected reference depth levels, using all floats from the depth interval $\pm 500 \mathrm{~m}$ around a particular reference level. The geostrophic relation is used to reduce the estimated Lagrangian float velocities from the measured float depth to the reference depth:

$$
\frac{\partial \boldsymbol{V}}{\partial z}=-\frac{g}{f \bar{\rho}}(\boldsymbol{k} \times \nabla \rho),
$$

where $\boldsymbol{V}$ is the Lagrangian horizontal velocity, $g$ is the acceleration due to gravity, $f$ is the Coriolis parameter, $\rho$ is the water density (obtained from the MEDTRANS climatology), and $\bar{\rho}$ is the characteristic value of $\rho$. Using floats from a layer, instead of a fixed level, significantly enhances the number of floats in each of the square and adds to the robustness of the results. The Eulerian mean velocities and the associated errors are further computed in each of the $1^{\circ} \times 1^{\circ}$

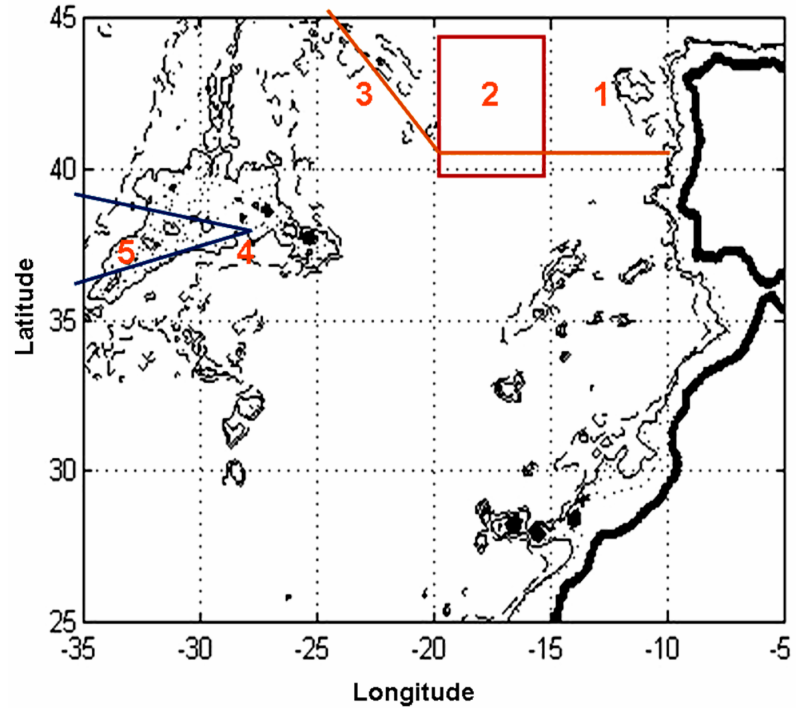

Figure A1. A map of sections along which comparison with the previous literature results in $5^{\circ} \times 5^{\circ}$ squares are made: blue line Hinrichsen and Tomczak (1993); orange line - Alvaréz et al. (2004); red square - Barbero et al. (2010). Squares, where the results are averaged are numbered.

squares. To account for the difference in the float sampling periods, the Lagrangian velocities in the means are weighted with the respective sampling periods (Lavender et al., 2005). The velocity errors are computed as $v_{\text {err }}=z_{95} \mathrm{SD} / \sqrt{n}$, where $n$ is the number of the data point, SD is the mean standard deviation of meridional and zonal components of the flow and $z_{95}$ is the $95 \%$ confidence interval of the Student's $t$ distribution. To increase the robustness of the results, we only used the mean velocities which exceed $v_{\text {err }}$.

The errors in estimation of current velocities, derived from Argo floats, are known to mostly be related to the float drift during its ascending/descending cycles and are estimated to be on average within $4 \mathrm{~cm} \mathrm{~s}^{-1}$ (Rosell-Fieschi et al., 2015). Taking SD $=4 \mathrm{~cm} \mathrm{~s}^{-1}$, we can estimate the minimum number of velocity samples needed for obtaining current velocity with a selected precision. The error in the current velocity of $1 \mathrm{~cm} \mathrm{~s}^{-1}$ or less requires around 60 velocity samples, $1.5 \mathrm{~cm} \mathrm{~s}^{-1}$ around 30 and $2 \mathrm{~cm} \mathrm{~s}^{-1}$ around 18 . At $1000 \mathrm{~m}$ about $40 \%$ of the grid cells satisfied the first criterion, $60 \%$ - the second one and $80 \%$ - the third one. At $1500 \mathrm{~m}$ the corresponding percentages are 15,40 , and $70 \%$. Therefore, the typical accuracy of the velocity estimates at $1000 \mathrm{~m}$ depth is of the order of $1.5 \mathrm{~cm} \mathrm{~s}^{-1}$, and at $1500 \mathrm{~m}$ depth $-2 \mathrm{~cm} \mathrm{~s}^{-1}$. As the Eulerian velocity fields are plotted, the outliers are eliminated using the discrete cosine transform - penalised least square method (Garcia, 2011). This filtering is not applied at the steep sloping topography, where a rapid variation of current velocity (topographically trapped flows) is expected. 
Table A1. A comparison of percentages obtained by applying the OMP analysis. The column "Lit." shows the range of percentages of a source water type in a literature source, the definitions of source water types characteristics from which are used to derive source water types characteristics for this study. The difference is computed between the mean values in a $5^{\circ} \times 5^{\circ}$ square (Fig. A1) between a literature source and this work.

\begin{tabular}{crrrrrr}
\hline & Lit. this paper (difference) & \multicolumn{2}{c}{ Lit. this paper (difference) } & \multicolumn{2}{c}{ Lit. this paper (difference) } \\
\cline { 2 - 7 } & \multicolumn{2}{c}{ NACW, $800 \mathrm{~m}$} & \multicolumn{2}{c}{ MW, $1000 \mathrm{~m}$} & \multicolumn{3}{c}{ LSW/NADW, $1000 \mathrm{~m}$} \\
\hline 1 & $50-60^{a}$ & $57(-2 \%)$ & $60^{\mathrm{a}}$ & $45(-15 \%)$ & $30-50^{\mathrm{a}}$ & $29(-12 \%)$ \\
2 & $60-80^{\mathrm{a}}, 70^{\mathrm{b}}$ & $72(-2 \%)$ & $40-50^{\mathrm{a}}, 30-50^{\mathrm{b}}$ & $35(-11 \%)$ & $50-60^{\mathrm{a}} 70^{\mathrm{b}}$ & $46(-9 \%)$ \\
3 & $80-90^{\mathrm{a}}$ & $76(-9 \%)$ & $20-40^{\mathrm{a}}$ & $25(-5 \%)$ & $50-70^{\mathrm{a}}$ & $62(-2 \%)$ \\
4 & $85^{\mathrm{c}}$ & $78(-8 \%)$ & $5^{\mathrm{c}}$ & $22(-17 \%)$ & $76^{\mathrm{c}}$ & $54(-23 \%)$ \\
5 & $82^{\mathrm{c}}$ & $73(-9 \%)$ & $6^{\mathrm{c}}$ & $20(-14 \%)$ & $81^{\mathrm{c}}$ & $61(-20 \%)$ \\
\hline
\end{tabular}

${ }^{\mathrm{a}}$ Alvaréz et al. (2004), ${ }^{\mathrm{b}}$ Barbero et al. (2010), ${ }^{\mathrm{c}}$ Hinrichsen and Tomczak (1993).

\section{A2 Comparison of our results with some previous studies}

This section presents a comparison of the results of this study with some previous applications of the OMP analysis to individual synoptic sections in the study region, where authors used a similar definition of the characteristics of the source water types (Hinrichsen and Tomczak, 1993; Alvares et al., 2004; Barbero et al., 2010). The results, presented in Fig. A1 and Table A1 in Appendix, show good correspondence. For comparison MW concentrations are derived close to the level of its maximum $(1000 \mathrm{~m})$, while NACW and LSW/NADW concentrations are taken within the layer of their strong vertical gradients (at 800 and $1000 \mathrm{~m}$, respectively). The differences in the percentages between the studies are mostly within 10-20\%: on the order of 5\% for NACW, $10-15 \%$ for MW and 10-20\% for LSW/NADW. The differences are partly the result of deviations in definitions of the characteristics of the source water types, which are seen as the stable bias in-between the studies. Synoptic variability also affects individual sections versus the climatic distribution studied here. A slightly worse correspondence for LSW/NADW with Hinrichsen and Tomczak (1993), the squares 4 and 5, is due to the very rapid vertical variation of the source water type contents at $1000 \mathrm{~m}$ depth (Fig. 9c, d). 
Acknowledgements. The authors acknowledge the scientific project MEDTRANS (PTDC/MAR/117265/2010), sponsored by the Portuguese Foundation for Science and Technology (FCT) and the MARE - Marine and Environmental Sciences Centre of the University of Lisbon (CO-Pest-OE/MAR/UI0199/2011). I. Bashmachnikov also acknowledges the contract C2008-UL-CO-3 of Ciência 2008 between Foundation for Science and Technology (FCT) and the University of Lisbon (UL) and Federico Ienna for help in preparation of the manuscript for publication. The authors also acknowledge the data centres, from where the data were used for this study: MEDTRANS climatology from MARE-University of Lisbon (http://www.mare-centre.pt/en/research/medtrans-data), the World Ocean Atlas climatology from NOAA National Center for Environmental Information (http://www.nodc.noaa.gov/OC5/woa13), the WOCE Subsurface Float Data Assembly Center from the Woods Hole Oceanographic Institute (http://wfdac.whoi.edu/), the Coriolis operational data centre from IFREMER (ftp://ftp.ifremer.fr) and GEBCO's bathymetry data (http: //www.gebco.net/data_and_products/gridded_bathymetry_data/).

Edited by: M. Hoppema

\section{References}

Aiki, H. and Yamagata, T.: A numerical study on the successive formation of Meddy-like lenses, J. Geophys. Res., 109, C06020, doi:10.1029/2003JC001952, 2004.

Alvaréz, M., Péres, F. F., Bryden, H., and Ríos, A. F.: Physical and biogeochemical transports structure in the North Atlantic subpolar gyre, J. Geophys. Res., 109, C03027, doi:10.1029/2003JC002015, 2004

Ambar, I. and Howe, M. R.: Observations of the Mediterranean outflow, I. Mixing in the Mediterranean outflow, Deep-Sea Res., 26, 535-554, 1979.

Ambar, I., Serra, N., Neves, F., and Ferreira, T.: Observations of the Mediterranean Undercurrent and eddies in the Gulf of Cadiz during 2001, J. Mar. Sys., 71, 195-220, 2008.

Anderson, L. A. and Sarmiento, J. L.: Redfield ratios of remineralization determined by nutrient data analysis, Global Biogeochem. Cy., 8, 65-80, 1994.

Arhan, M.: The North Atlantic Current and Subarctic Intermediate Water. J. Mar. Res., 48, 109-144, 1990.

Arhan, M., de Verdière, A. C., and Mémery, L.: The eastern boundary of the subtropical North Atlantic, J. Phys. Oceanogr., 24, 1295-1316, 1994.

Barbero, L., González-Dávila, M., Santana-Casiano, J. M., and Álvarez, M.: Variability of the water mass transports and fluxes in the eastern North Atlantic during 2001, J. Geophys. Res., 115, C03023, doi:10.1029/2008JC005212, 2010.

Barbosa Aguiar, A. C., Peliz, A., Neves, F., Bashmachnikov, I., and Carton, X.: Mediterranean outflow transports and entrainment estimates from observations and high resolution modeling, Prog. Oceanogr., 131, 33-45, 2015.

Baringer, M. O. and Price, J. F.: Mixing and spreading of the Mediterranean Outflow, J. Phys. Oceanogr., 27, 1654-1677, 1997.

Barnes, S. L.: A Technique for Maximizing Details in Numerical Weather Map Analysis, J. Appl. Meteorol., 3, 396-409, 1964.
Bashmachnikov, I., Mohn, C., Pelegrí, J. L., Martins A., Machín, F., Jose, F., and White, M.: Interaction of Mediterranean water eddies with Sedlo and Seine seamounts, subtropical Northeast Atlantic, Deep-Sea Res. Pt. II, 56, 2593-2605, 2009.

Bashmachnikov, I., Neves, F., Nascimento, A., Medeiros, J., Dias, J., Ambar, I., and Carton, X.: Temperature-salinity distribution in the Northeast Atlantic from ship and Argo vertical casts, Ocean Sci., 11, 215-236, doi:10.5194/os-11-215-2015, 2015a.

Bashmachnikov, I., Neves, F., Calheiros, T., and Carton, X.: Properties and pathways of Mediterranean water eddies in the Atlantic, Prog. Oceanogr., 137A, 149-172, 2015 b.

Bower, A. S., Le Cann, H., Rossby, T., Zenk, W., Gould, J., Speer, K., Richardson, P. L., Prater, M. D., and Zhang, H.-M.: Directly measured mid-depth circulation in the North Atlantic Ocean, Nature, 419, 603-607, 2002a.

Bower, A. S., Lozier, M. S., Gary, S. F., and Böning, C. W.: Interior pathways of the North Atlantic meridional overturning circulation, Nature, 459, 243-247, 2009.

Bower, A., Serra, N., and Ambar, I.: Structure of the Mediterranean undercurrent and Mediterranean water spreading around the southwestern Iberian Peninsula, J. Geophys. Res., 107, 3161 , doi:10.1029/2001JC001007, 2002b.

Brix, H. and Gerdes, R.: North Atlantic Deep Water and Antarctic Bottom Water: Their interaction and influence on the variability of the global ocean circulation, J. Geophys. Res., 108, 3022, doi:10.1029/2002JC001335, 2003.

Cabeçadas, G., Brogueira, M. J., and Gonçalves, C.: The chemistry of Mediterranean outflow and its interactions with surrounding waters, Deep-Sea Res. Pt. II, 49, 4263-4270, 2002.

Carracedo, L. I., Gilcoto, M., Mercier, H., and Pérez, F. F.: Seasonal dynamics in the Azores-Gibraltar Strait region: A climatologically-based study, Prog. Oceanogr., 122, 116-130, 2014.

Cianca, A., Santana, R., Marrero, J. P., Rueda, M. J., and Llinás, O.: Modal composition of the central water in the North Atlantic subtropical gyre, Ocean Sci. Discuss., 6, 2487-2506, doi:10.5194/osd-6-2487-2009, 2009.

Dafner, E. V., Boscolo, R., and Bryden, H. L.: The N : Si : P molar ratio in the Strait of Gibraltar, Geophys. Res. Lett., 30, 1506 , doi:10.1029/2002GL016274, 2003.

Daniault, N., Mazé, J. P., and Arhan, M.: Circulation and mixing of Mediterranean Water west of the Iberian Peninsula, Deep-Sea Res. Pt. I, 41, 1685-1714, 1994.

Davis, R. E., Killworth, P. D., and Blundell, J. R.: Comparison of autonomous Lagrangian circulation explorer and fine resolution Antarctic model results in the South Atlantic, J. Geophys. Res., 101, 855-884, 1996.

Gasparin, F., Maes, C., Sudre, J., Garcon, V., and Ganachaud, A.: Water mass analysis of the Coral Sea through an Optimum Multiparameter method, J. Geophys. Res., C119, 7229-7244, 2014.

Garcia, D.: A fast all-in-one method for automated post-processing of PIV data, Experim. Fluid., 50, 1247-1259, 2011.

Hansen, B. and Østerhus, S.: North Atlantic-Nordic Seas exchanges, Prog. Oceanogr., 45, 109-208, 2000.

Harvey, J. and Arhan, M.: The water masses in central North Atlantic in 1983-84, J. Phys. Oceanogr., 18, 1855-1875, 1988.

Hinrichsen, H.-H. and Tomczak, M.: Optimum multiparameter analysis of the water mass structure in the Western North Atlantic Ocean, J. Geophys. Res., 98, 10155-10169, 1993. 
Iorga, M. C. and Lozier, M. S.: Signatures of the Mediterranean outflow from a North Atlantic climatology, 1. Salinity and density fields, J. Geophys. Res., 104, 25985-26009, 1999a.

Iorga, M. C. and Lozier, M. S.: Signatures of the Mediterranean outflow from a North Atlantic climatology, 2. Diagnostic velocity fields, J. Geophys. Res., 104, 26011-26029, 1999 b.

Jackett, D. R. and McDougall, T. J.: A Neutral Density Variable for the World's Oceans, J. Phys. Oceanogr., 27, 237-263, 1997.

Karstensen, J. and Tomczak, M.: Ventilation processes and water mass ages in the thermocline of the southeast Indian Ocean, Geophys. Res. Lett., 24, 2777-2780, 1997.

Klein, B. and Tomczak, M.: Identification of diapycnal mixing through optimum multiparameter analysis: 2 . Evidence for unidirectional diapycnal mixing in the front between North and South Atlantic Central Water, J. Geophys. Res., 99, 25275-25280, 1994.

Krémeur, A.-S., Lévy, M., Aumont, O., and Reverdin, G.: Impact of the subtropical mode water biogeochemical properties on primary production in the North Atlantic: New insights from an idealized model study, J. Geophys. Res., 114, C07019, doi:10.1029/2008JC005161, 2009.

Lavender, K. L., Owens, W. B., and Davis, R. E.: The mid-depth circulation of the subpolar North Atlantic Ocean as measured by subsurface floats, Deep-Sea Res. Pt. I, 52), 767-785, 2005.

Llinás, O., Rueda, M. J., Pérez Marrero, J., Pérez-Martell, E., Santana, R., Villagarcía, M. G., Cianca, A., Godoy, J., and Maroto, L.: Variability of the Antarctic intermediate waters in the northern Canary box, Deep-Sea Res. Pt. II, 49, 3441-3453, 2002.

Louarn, E. and Morin, P.: Antarctic Intermediate Water influence on Mediterranean Sea Water outflow, Deep-Sea Res. Pt. I, 58, 932-942, 2011.

Machín, F., Hernández-Guerra, A., and Pelegrí, J. L.: Mass fluxes in the Canary Basin, Prog. Oceanogr., 70, 416-447, 2006.

Machín, F. and Pelegrí, J.L.: Northward Penetration of Antarctic Intermediate Water off Northwest Africa, J. Phys. Oceanogr., 39, 512-535, 2009.

Mackas, D. L., Denman, K. L., and Bennett, A. F.: Least squares multiple tracer analysis of water mass composition, J. Geophys. Res., 92, 2907-2918, 1987.

Maximenko N. A. and Orlov, O. I.: Integral characteristics of the core of quasi-stationary "Gauss" vortex in homogeneous and shear flows, Oceanol. 31, 34-41, 1991 (in Russian).

Mazé, J. P., Arhan, M., and Mercier, H.: Volume budget of the eastern boundary layer off the Iberian Peninsula, Deep-Sea Res. Pt. I, 44, 1543-1574, 1997.

Mazé, G. and Marshall, J.: Diagnosing the observed seasonal cycle of Atlantic subtropical mode water using potential vorticity and its attendant theorems, J. Phys. Oceanogr., 41, 1986-1999, 2011.

McCartney, M. S. and Talley, L. D.: The Subpolar Mode Water of the North Atlantic Ocean, J. Phys. Oceanogr., 12, 1169-1188, 1982.

McCartney, M. S.: The subtropical recirculation of Mode Waters, J. Mar. Res., 40, Supplement, 427-464, 1982.

McDougall, T. J.: Neutral density surfaces, J. Phys. Oceanogr., 17, 1950-1964, 1987.

MODE Group: The Mid-Ocean Dynamics Experiment, Deep-Sea Res., 25, 859-910, 1978.

Morel, Y.: The Influence of an Upper Thermocline Current on Intrathermocline Eddies, J. Phys. Oceanogr., 25, 3247-3252, 1995.
New, A. L., Jia, Y., Coulibaly, M., and Dengg, J.: On the role of the Azores current in the ventilation of the North Atlantic Ocean, Prog. Oceanogr., 48, 163-194, 2001.

Ollitrault, M. and Colin de Verdière, A.: The Ocean General Circulation near 1000-m Depth, J. Phys. Oceanogr., 44, 384-409, 2014.

Orsi, A. H., Jacobs, S. S., Gordon, A. L., and Visbeck, M.: Cooling and ventilating the Abyssal Ocean, Geophys. Res. Lett., 28, 2923-2926, 2001.

Paillet, J. and Arhan, M.: Shallow picnocline and Mode water subduction in the Eastern North Atlantic, J. Phys. Oceanogr., 26, 96-114, 1996a.

Paillet, J. and Arhan, M.: Oceanic ventilation in the Eastern North Atlantic, J. Phys. Oceanogr., 26, 2036-2052, 1996b.

Pastor, M. V., Peña-Izquierdo, J., Pelegrí, J. L., and Marrero-Díaz, A.: Meridional changes in water mass distributions off NW Africa during November 2007/2008, Cienc. Mar., 38, 223-244, 2012.

Paillet, J., Arhan, M., and McCartney, M. S.: Spreading of Labrador sea water in the eastern North Atlantic, J. Geophys. Res., 103, 10223-10239, 1998.

Pedlosky, J.: Ocean Circulation Theory, 2nd Edn., Springer, New York, 453 pp., 1998.

Peña-Izquierdo, J., van Sebille, E., Pelegrí, J. L., Sprintall, J., Mason, E., Llanillo, P. J., and Machín, F.: Water mass pathways to the North Atlantic oxygen minimum zone, J. Geophys. Res., C120, 3350-3372, 2015.

Pérez, F. F., Ríos, A. F., Castro, C. G., and Fraga, F.: Mixing analysis of nutrients, oxygen and dissolved inorganic carbon in the upper and middle North Atlantic Ocean east of the Azores, J. Mar. Sys., 16, 219-233, 1998.

Pérez, F. F., Mintrop, L., Llinás, O., Glez-Dávila, M., Castro, C. G., Alvaréz, M., Körtzinger, A., Santana-Casiano, M., Rueda, M. J., and Ríos, A. F.: Mixing analysis of nutrients, oxygen and dissolved inorganic carbon in Canary Islands region, J. Mar. Sys., 28, 183-201, 2001.

Pérez, F. F., Mouriño, C., Fraga, F., and Rios, A. F.: Displacement of water masses and remineralization rates off the Iberian Peninsula by nutrient anomalies, J. Mar. Res., 51, 869-892, 1993.

Pingree, R. D., Garcia-Soto, C., and Sinha, B.: Position and structure of the subtropical/Azores front region from combined Lagrangian and remote sensing (IR/altimiter/SeaWiFS) measurements, J. Mar. Biol. Assoc. UK, 79, 769-792, 1999.

Pollard, R. T. and Pu, S.: Structure and circulation of the upper Atlantic ocean northeast of the Azores, Prog. Oceanogr., 14, 443462, 1985.

Pollard, R. T., Griffiths, M. J., Cunningham, S. A., Read, J. F., Pérez, F. F., and Rios, A. F.: Vivaldi 1991- a study of the formation, circulation and ventilation of Eastern North Atlantic Central Water, Prog. Oceanogr., 37, 167-192, 1996.

Poole, R. and Tomczak, M.: Optimum multiparameter analysis of the water mass structure in the Atlantic Ocean thermocline, Deep-Sea Res. Pt. I, 46, 1895-1921, 1999.

Price, J. F., Baringer, M., Lueck, R. G., Johnson, G. C., Ambar, I., Parrilla, G., Cantos, A., Kennelly, M. A., and Sanford, T. B.: Mediterranean outflow mixing and dynamics, Science, 259, 1277-1282, 1993.

Redfield, A. C., Ketchum, B. H., and Richards, F. A.: The influence of organisms on the composition of sea-water, in: The Sea: Ideas 
and Observations on Progress in the Study of the Seas, edited by: Hill, M. N., Vol. 2, Wiley, London, 26-77, 1963.

Rhein, M. and Hinrichsen, H.-H.: Modification of Mediterranean Water in the Gulf of Cadiz, studied with hydrographic, nutrient and chlorofluoromethane data, Deep-Sea Res. Pt. I, 40, 267-291, 1993.

Richardson, P. L., McCartney, M. S., and Maillard, C.: A search for meddies in historical data, Dynam. Atmos. Oc., 15, 241-265, 1991.

Richardson, P. L., Bower, A. S., and Zenk, W.: A census of Meddies tracked by floats, Prog. Oceanogr., 45, 209-250, 2000.

Rosell-Fieschi, M., Pelegrí, J. L., and Gourrion, J.: Zonal jets in the equatorial Atlantic Ocean, Prog. Oceanogr., 130, 1-18, 2015.

Rossby, H. T., Levine, E. R., and Connors, D. N.: The isopycnal swallow float - a simple device for tracking water parcels in the ocean, in: Essays in Oceanography: a tribute to John Swallow, Prog. Oceanogr., 14, 511-525, 1985.

Schmitz Jr., W. J.: On the World Ocean Circulation, Volume 1. Some Global Features/North Atlantic Circulation (No. WHOI96-03-VOL-1), Woods Hole Oceanographic Institution MA, 1996.

Siedler, G., Kuhl, A., and Zenk, W.: The Madeira mode water, J. Phys. Oceanogr., 17, 1561-1570, 1987.

Sparrow, M., Boebel, O., Zervakis, V., Zenk, W., Cantós-Figueroa, A., and Gould, W. J.: Two circulation regimes of the Mediterranean Outflow revealed by Lagrangian Measurements, J. Phys. Oceanogr., 32, 1322-1330, 2002.

Stramma, L., Brandt, P., Schafstall, J., Schott, F., Fischer, J., and Körtzinger, A.: Oxygen minimum zone in the North Atlantic south and east of the Cape Verde Islands, J. Geophys. Res., 113, C04014, doi:10.1029/2007JC004369, 2008.

Straneo, F., Pickart, R. S., and Lavender, K.: Spreading of Labrador sea water: an advective-diffusive study based on Lagrangian data, Deep-Sea Res. Pt. I, 50, 7001-719, 2003.
Talley, L. D., and McCartney, M. S.: Distribution and circulation of Labrador Sea Water, J. Phys. Oceanogr., 12, 1189-1205, 1982.

Tomczak, M.: A multiparameter extension of temperature/salinity diagram techniques for the analysis of non-isopycnal mixing, Prog. Oceanogr., 10, 147-171, 1981.

Tomczak, M. and Godfrey, J. S.: Regional Oceanography: An introduction, available from: http://www.es.flinders.edu.au/ mattom/ regoc/pdfversion.html (last accessed: 2 April 2015), 2003.

Tomczak, M. and Large, D. G.: Optimum multiparameter analysis of mixing in the thermocline of the eastern Indian Ocean, J. Geophys. Res., 94, 16141-16149, 1989.

Tsuchiya, M., Talley, L. D., and McCartney, M. S.: An eastern Atlantic section from Iceland southward across the equator, DeepSea Res., 39, 1885-1917, 1992.

Tsuchiya, M.: Circulation of the Antarctic Intermediate Water in the North Atlantic Ocean, J. Mar. Res., 47, 747-755, 1989.

van Aken, H. M.: The hydrography of the mid-latitude northeast Atlantic Ocean I: The deep water masses, Deep-Sea Res. Pt. I, 47, 757-788, 2000a.

van Aken, H. M.: The hydrography of the mid-latitude northeast Atlantic Ocean II: The intermediate water masses, Deep-Sea Res. Pt. I, 47, 789-824, 2000b.

van Aken, H. M.: The hydrography of the mid-latitude northeast Atlantic Ocean III: The subducted thermocline water mass, DeepSea Res. Pt. I, 48, 237-267, 2001.

Zika, J. D., McDougall, T. J., and Sloyan, B. M.: Weak mixing in the Eastern North Atlantic: an application of the Tracer-Contour Inverse Method, J. Phys. Oceanogr., 40, 1881-1893, 2010. 